Research Article

\title{
Hydrogeochemical Features and Genesis of Confined Groundwater and Health Perspectives for Sustainable Development in Urban Hengshui, North China Plain
}

\author{
Yong Xiao $\mathbb{D}^{1},{ }^{1}$ Kui Liu $\mathbb{D}^{1},{ }^{1}$ Qichen Hao $\mathbb{D}^{\circ},{ }^{2}$ Jianfeng Li $\mathbb{D}{ }^{2}{ }^{2}$ Yunhui Zhang $\mathbb{D}^{1}{ }^{1}$ \\ Weizhe Cui $\left({ }^{\circ},{ }^{2}\right.$ Limao qin, ${ }^{1}$ and Qiuming Pei $\mathbb{( I D}^{1}$ \\ ${ }^{1}$ Faculty of Geosciences and Environmental Engineering, Southwest Jiaotong University, Chengdu 611756, China \\ ${ }^{2}$ Institute of Hydrogeology and Environmental Geology, Chinese Academy of Geological Science, Shijiazhuang 050061, China \\ Correspondence should be addressed to Qichen Hao; haoqichen_iheg@163.com
}

Received 6 February 2021; Revised 11 March 2021; Accepted 25 March 2021; Published 16 April 2021

Academic Editor: Junbing Pu

Copyright (c) 2021 Yong Xiao et al. This is an open access article distributed under the Creative Commons Attribution License, which permits unrestricted use, distribution, and reproduction in any medium, provided the original work is properly cited.

\begin{abstract}
Groundwater in confined aquifers is the preferred water resource worldwide, and its hydrochemical quality is the premise for sustainable development. A systematic hydrogeochemical research was conducted to get insight into the hydrochemical characteristics, genesis, and potential health threats of confined groundwater, based on analytical data of 45 groundwater samples collected from the urban area of Hengshui, Central North China Plain (NCP). The results showed most groundwater had desirable hydrochemical quality with a nearly neutral to slightly alkaline nature and dominantly soft-fresh $\mathrm{Cl}-\mathrm{Na}$ face. Solute chemistry was governed by rock-water interaction including minerals dissolution and ion exchange, but out of the anthropogenic influences. All nitrogen pollutants and $\mathrm{Zn}$ were within the desirable limit, while $\mathrm{F}^{-}, \mathrm{Mn}$, and Fe were beyond the desirable limit recommended by WHO in $28.9 \%, 15.6 \%$, and $68.9 \%$ of samples. Overall chronic health risk from these toxic elements was identified in terms of various populations and mainly contributed by $\mathrm{F}^{-}$. Infants were more prone to the health risks of aqueous pollutants. Differential water supplies based on hydrochemical quality are recommended, and water improvement measures are suggested to be conducted aiming at the harmful fluoride in confined groundwater. The present research could provide valuable references for the health sustainability of confined groundwater utilization in sedimentary plains like NCP worldwide.
\end{abstract}

\section{Introduction}

The available freshwater is dominantly stored underground and accounts for approximately $96 \%$ of the total liquid freshwater on Earth [1]. Groundwater is a significant water source enabling the security of water and food and the key factor lifting the rural populations out of poverty over the world [2-5], especially in arid and semiarid regions with relative scarcity of surface water [6-10]. The availability of groundwater resources for the human community is limited not only by the water quantity but also by the hydrochemical quality $[11,12]$. A full understanding of the hydrochemical features, mechanisms, and quality is the premise of effective management and sustainable development of groundwater resources in any region across the world $[13,14]$.
Groundwater chemistry is influenced or even governed by many factors including natural and anthropogenic ones $[15,16]$. Generally, the natural groundwater chemistry is determined by the hydrochemical components of recharge water, lithology of aquifers along the groundwater flow path, residence time, groundwater hydrodynamic, and evaporation [17-21]. These factors are fundamental for the natural formation and evolution of groundwater chemical components [22-25], while anthropogenic factors from all aspects of human society including domestic, agricultural, and industrial activities can dramatically modify the composition of groundwater chemistry through direct pollutants input or indirect change of the hydrogeochemical conditions of natural mechanisms [26-31]. The driving forces from the human community to the evolution of groundwater 
chemistry have more significant influences on the phreatic aquifers rather than the confined aquifers due to the protection of aquitards. In addition, evaporation usually has great effects on the salinity of phreatic groundwater, which would not occur in the confined aquifers [23, 32-34]. Thus, phreatic groundwater is found with poorer hydrochemical quality than confined groundwater [16, 35-39].

Attention has been concentratedly paid to the hydrochemistry and responsibilities for the poor quality of phreatic groundwater in the past decades [40-44] due to the frangibility of unconfined aquifers to the influences of external pollutions and extreme hydrological events. Great achievements have been obtained through these efforts on the understanding of hydrochemical features, evolutions, and mechanisms of shallow underground aquatic systems and effectively guided groundwater management globally $[14,44-47]$. However, the confined groundwater is not lucky as the phreatic one. It is rarely concerned regarding the hydrogeochemical quality because it is regarded as the cleanest and best quality water beneath the traditional viewpoint. Although it is rare for confined groundwater affected by external factors on its hydrochemical quality, the potential poor quality as a result of the internal factors cannot be evaded [48]. Geogenic poor quality of groundwater has been one of the greatest threats to the water supply for human society and is widely reported in many regions across the world [48-54]. Thus, concerns on the hydrochemical quality and genesis are indispensable for confined groundwater if utilized for the human community.

The present research focuses on the hydrochemistry and health implication of confined water in large sedimentary plains. A subarea of the North China Plain (NCP), one of the global research hotspots of Anthropocene groundwater science, was investigated to provide references to the sustainable development of confined groundwater resources in other similar great sedimentary plains worldwide. The major aims of the present research were to (1) get insight into the hydrogeochemical features of confined groundwater, (2) reveal the mechanisms forming the hydrochemistry, (3) determine the toxic elements and their potential health threats, and (4) finally propose scientific management suggestions for the health sustainability of groundwater resources.

\section{Study Area}

The study area is located in the central area of the NCP (Figure 1). It lies between the latitude of $37^{\circ} 36^{\prime} 10^{\prime \prime} \mathrm{N}$ $37^{\circ} 49^{\prime} 55^{\prime \prime} \mathrm{N}$ and the longitude of $115^{\circ} 25^{\prime} 17^{\prime \prime} \mathrm{E}-115^{\circ} 51^{\prime} 12^{\prime \prime} \mathrm{E}$ and spreads over an area of $591 \mathrm{~km}^{2}$. It represents semiarid continental monsoon conditions with an annual average temperature of $12.7^{\circ} \mathrm{C}$. The average annual rainfall is approximately $500 \mathrm{~mm}$ where $75 \%$ occurs during the rainy season from June to September. The annual evaporation rate varies from $\sim 1,300 \mathrm{~mm}$ to $\sim 2,600 \mathrm{~mm}$, approximating $3-5$ times of the local rainfall. The land use type in this region is dominated by agricultural land, followed by urban land and industrial land.
Geologically, the study area belongs to the alluvial-lacustrine plain of the central NCP. The NCP is one of the largest sedimentary plains in the world and formed during the Cenozoic and Mesozoic era. This area is flat and descends slightly from the west towards the east with an elevation in the range of $22-27 \mathrm{~m}$. Groundwater in this area mainly occurs in the Quaternary deposits with a thickness of more than $500 \mathrm{~m}$ [55]. This large Quaternary groundwater system provides the major quantity of water resource for the local development in various social-economic and ecological aspects.

The lithology of the Quaternary deposits varies from pebble to clay and silt, resulting in multiple aquifer groups vertically (Figure 2). The first continuous and stable aquitard is observed at the depth of $50-80 \mathrm{~m}$ below the ground surface. Generally, aquifers above this aquitard are defined as the phreatic aquifers, and those below this are identified as confined aquifers. Due to the wide distribution of saline water in phreatic aquifers [49], confined aquifers are regarded as the most potential aquifers supporting the development of the study area $[33,55]$. The confined aquifers have a relatively poor water alternative ability and are mainly recharged and discharged through the lateral and vertical flow naturally.

Owing to the scarcity of surface water and high salinity of phreatic groundwater, water supply for various consumers of human society in this region mainly depends on the confined groundwater. Thus, human exploitation has become the main discharge form of the confined aquifers in the past decades [50]. In particular, agricultural irrigation, the largest water consumer, in recent decades has dominantly relied on confined groundwater [56], resulting in many groundwater depression cones in the confined aquifers as well as ground subsidence. These drastic changes of the hydraulic and geological environment also caused the evolution of the hydrogeochemical environment in confined aquifers and finally threatened the hydrochemical quality of groundwater [57], for example, the releasing of iodine into groundwater [58]. Thus, it is significantly necessary to perform targeted works to get insight into the hydrochemical quality, genesis, and potential quality issues of confined groundwater [59].

\section{Material and Methods}

3.1. Sampling and Analytical Techniques. In the present study, a total of 45 groundwater samples was collected from the confined aquifers across the study area (Figure 1(c)). All groundwaters were sampled from the boreholes at the depth of $150-700 \mathrm{~m}$. The water in boreholes was pumped for more than three times of borehole volume before sampling to remove the stagnant water in the boreholes. In situ hydrochemical parameters, such as $\mathrm{pH}$ and electrical conductivity (EC), were monitored and sampling was conducted only after these parameters being stable. The sampled groundwaters were collected in the ultrapure water plastic buckets of $2.5 \mathrm{~L}$ which had been thoroughly rinsed with the target water three times before sampling. All groundwater samples were sent to the Laboratory for analysis with the aid 


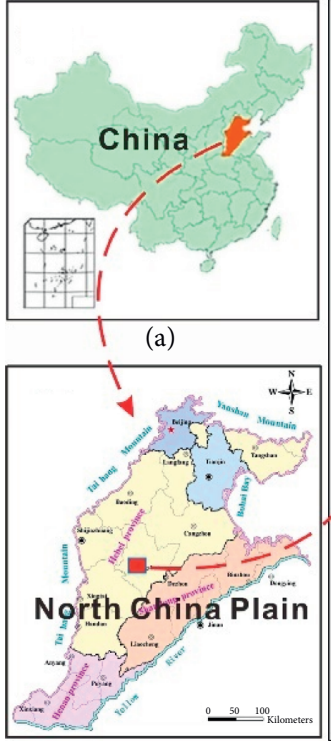

(b)

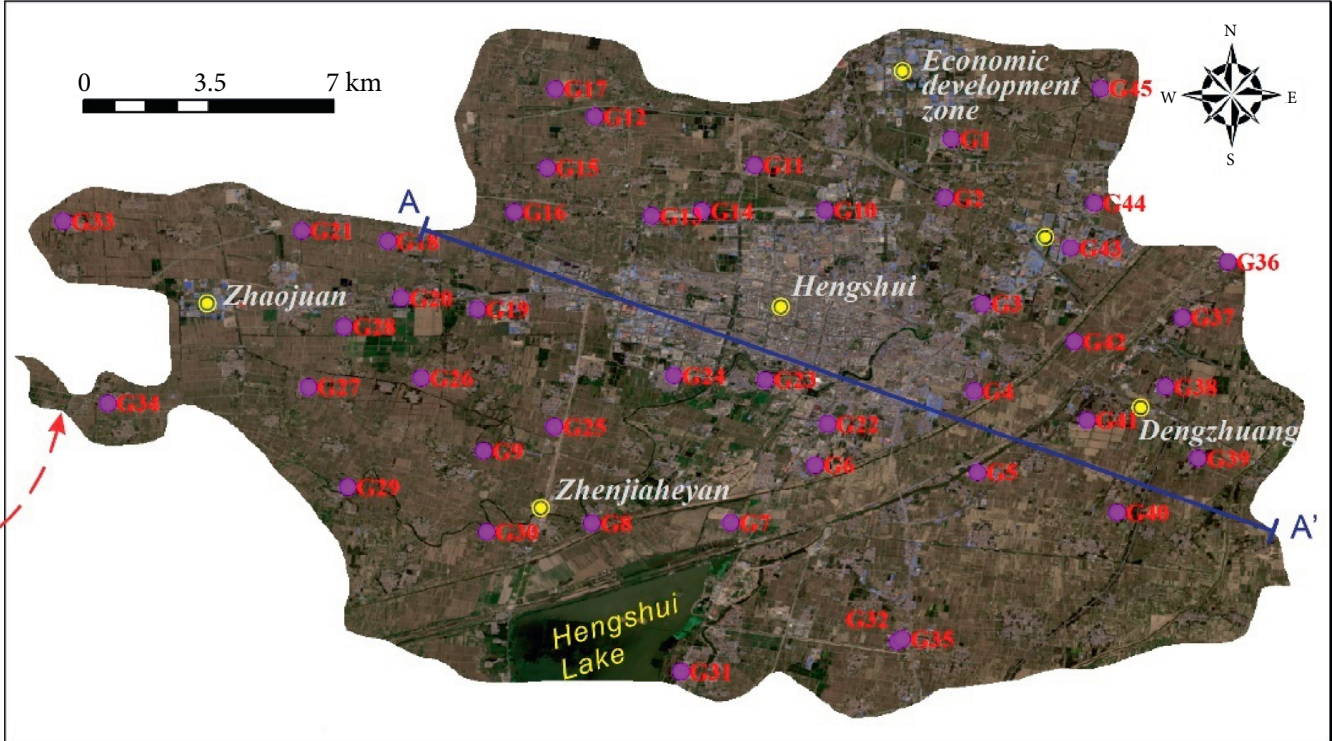

(c)

(-) Town

- Sampling site

$\longmapsto$ Section line

Figure 1: Location of the study area and sampling sites.

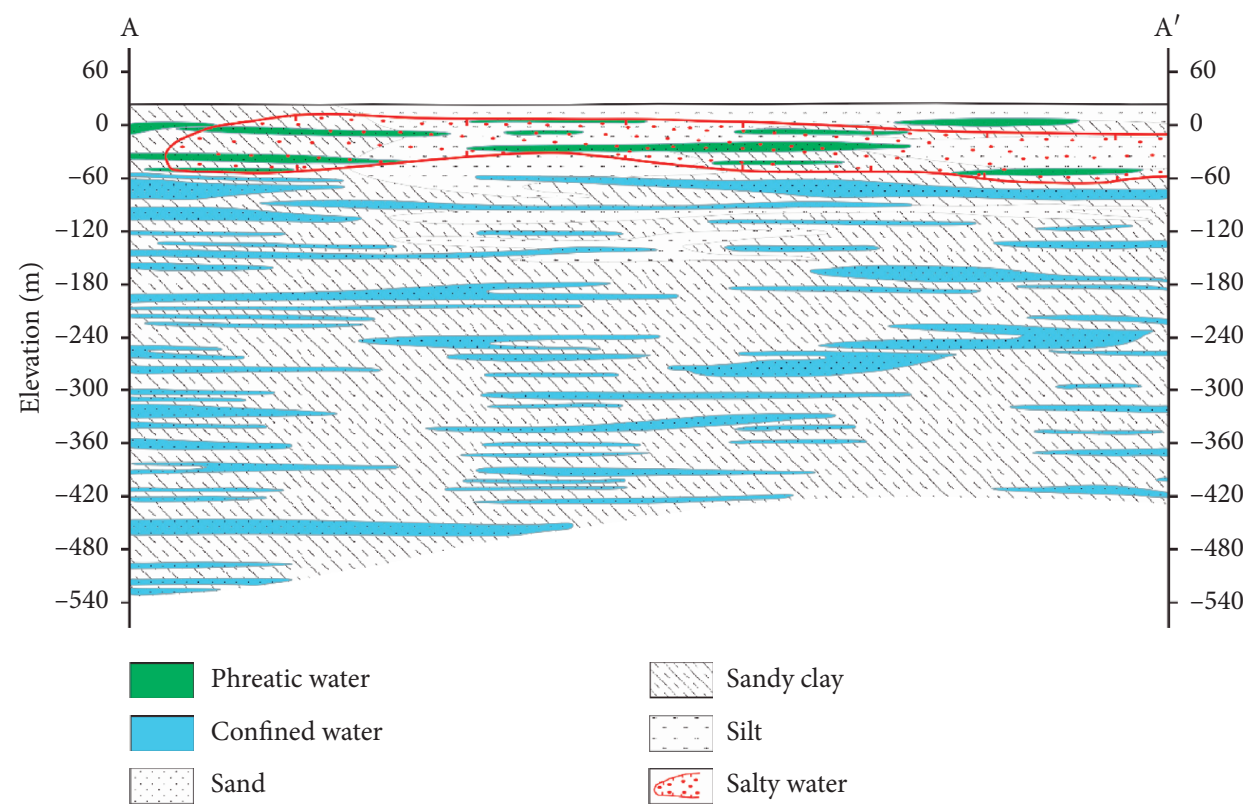

FIgURE 2: The hydrogeological cross section along the A-A'.

of incubators which could keep the samples in the condition of $4^{\circ} \mathrm{C}$ temperature.

The in situ parameters like $\mathrm{pH}$ and $\mathrm{EC}$ were obtained at the field with the aid of a multiparameter device (Multi 350i/ SET, Munich, Germany). The analysis of other chemical parameters was conducted in the Laboratory of Groundwater Sciences and Engineering of the Institute of Hydrogeology and Environmental Geology, Chinese Academy of
Geological Sciences. Major cation ions $\left(\mathrm{Ca}^{2+}, \mathrm{Mg}^{2+}, \mathrm{Na}^{+}\right.$, $\mathrm{K}^{+}$) and trace elements $(\mathrm{Zn}, \mathrm{Mn}, \mathrm{Fe})$ were determined using inductively coupled plasma-mass spectrometry (Agilent 7500ce ICP-MS, Tokyo, Japan). Ammonia-nitrogen $\left(\mathrm{NH}_{4}{ }^{+}\right)$ and anions including $\mathrm{Cl}^{-}, \mathrm{SO}_{4}{ }^{2-}, \mathrm{NO}_{3}{ }^{-}, \mathrm{NO}_{2}{ }^{-}, \mathrm{F}^{-}$were measured by ion chromatography (Shimadzu LC-10ADvp, Kyoto, Japan). $\mathrm{HCO}_{3}{ }^{-}$and total dissolved solids (TDS) were obtained with the aid of acid-base titration. Ionic charge 
balance was conducted to verify the accuracy of chemical analyses. The results showed the charge balance errors of all samples were within the permissible limit of $\pm 5 \%$, demonstrating reasonably good measurement accuracy.

3.2. Human Health Risk Assessment. Contaminants in groundwater could potentially threaten the health of human beings if exposed to contaminated water. This potential health threat could be identified with the aid of a quantitative model, namely, the human health risk assessment model (HHRA model) established by the United States Environmental Protection Agency [60]. Generally, contaminants in water could pose threats through multiple pathways, such as drinking water intake, dermal contact, and inhalation. As reported by previous research, drinking water intake pathway has higher risks than other pathways regarding the high content of toxic elements in water [38, 39, 61, 62]. Thus, the pathway of drinking water intake should be paid significant attention regardless of age and gender.

The procedure of HHRA includes the following three steps:

Step 1: computation of the chronic daily intake dose of potential contaminants in target water:

$$
\begin{aligned}
\mathrm{CDI}_{i} & =\frac{\left(C_{i} \times \mathrm{IR} \times \mathrm{EF} \times \mathrm{ED}\right)}{(\mathrm{BW} \times \mathrm{AT})}, \\
\mathrm{AT} & =\mathrm{ED} \times 365,
\end{aligned}
$$

where $\mathrm{CDI}_{i}$ signifies the chronic daily intake dose of contaminant $i ; C_{i}$ indicates the content of contaminant $i$ in target water; IR is the rate of water oral intake; EF represents the exposure frequency; ED and AT refer to exposure duration and average exposure time, respectively; BW signifies the mean body weight of the consumer.

Step 2: identification of the hazard quotient:

$$
\mathrm{HQ}_{i}=\frac{\mathrm{CDI}_{i}}{\mathrm{RfD}_{i}}
$$

where $\mathrm{HQ}_{i}$ expresses the probabilistic health risk posed by single contaminant $i ; \mathrm{RfD}_{i}$ denotes the reference dose of contaminants $i$ through the pathway of oral intake.

Step 3: synthetical assessment of the overall health risk:

$$
\mathrm{HI}=\mathrm{HQ}_{1}+\mathrm{HQ}_{2}+\ldots+\mathrm{HQ}_{i},
$$

where $\mathrm{HI}$ is the overall potential health risk posed by multiple contaminants in drinking water.

The parameters used in the HHRA model in the present study are listed in Table 1.

\section{Results and Discussion}

4.1. Physicochemical Characteristics of Groundwater. The physicochemical parameters of confined groundwater in the study area were statistically demonstrated in the box plots of Figure 3. The desirable limit of various indices recommended by the WHO [65] and the Chinese guideline [66] was also presented.

The $\mathrm{pH}$ of the sampling water had a range from 7.26 to 10.32 with an average of 8.14 , indicating a nearly neutral to slightly alkaline nature of confined groundwater. As shown in Figure 3(a), most of the groundwaters were with a $\mathrm{pH}$ value within the desirable range of 6.5-8.5 recommended by WHO [65]. About $22.2 \%$ of the total samples were found out of the $\mathrm{pH}$ desirable range and with a slightly more alkaline feature. A relatively large variation of EC values was observed from the sampled groundwaters with the range from $693 \mu \mathrm{S} / \mathrm{cm}$ to $4,637 \mu \mathrm{S} / \mathrm{cm}$ averaging at $1,128 \mu \mathrm{S} /$ $\mathrm{cm}$. The TDS also showed a relatively wide range from 467 $\mathrm{mg} / \mathrm{L}$ to $3,122 \mathrm{mg} / \mathrm{L}$ with an average of $681 \mathrm{mg} / \mathrm{L}$. Thus, groundwater had a large variation of salinity in the study area. However, most of the sampled waters had relatively low EC and TDS values, and only a small portion of samples had the EC and TDS beyond $2000 \mu \mathrm{S} / \mathrm{cm}$ and $1000 \mathrm{mg} / \mathrm{L}$, respectively (Figures 3(b) and 3(c)). The value of total hardness $(\mathrm{TH})$ was in a wide range from $13 \mathrm{mg} / \mathrm{L}$ to $1,416 \mathrm{mg} / \mathrm{L}$ with an average of $121 \mathrm{mg} / \mathrm{L}$. Groundwaters were dominantly with the $\mathrm{TH}$ value below the desirable limit of $450 \mathrm{mg} / \mathrm{L}$ and only 3 samples (6.7\%) beyond this limit. According to the integrated water quality categories based on TDS and TH (Figure 4), confined groundwater in the study area was predominantly soft-fresh water. Four samples $(8.9 \%)$ were observed falling in the moderately hard fresh category, one $(2.2 \%)$ in the moderately hard brackish category and another $(2.2 \%)$ in the hard brackish category. Only four groundwaters $(8.9 \%)$ were under the very hard brackish category.

The solute chemistry of confined groundwater was dominated by $\mathrm{Na}^{+}$for cations (Figure 5) with a range from $162 \mathrm{mg} / \mathrm{L}$ to $591 \mathrm{mg} / \mathrm{L}$ and averaging at $203 \mathrm{mg} / \mathrm{L} . \mathrm{Ca}^{2+}$ and $\mathrm{Mg}^{2+}$ ranked the second and third abundance in the major cations and varied from $4 \mathrm{mg} / \mathrm{L}$ to $221 \mathrm{mg} / \mathrm{L}$ and between $1 \mathrm{mg} / \mathrm{L}$ and $210 \mathrm{mg} / \mathrm{L}$, respectively, with an average of $25 \mathrm{mg} /$ $\mathrm{L}$ and $13 \mathrm{mg} / \mathrm{L}$. $\mathrm{K}^{+}$was the least abundant ion in major cations and ranged from $0.41 \mathrm{mg} / \mathrm{L}$ to $8.88 \mathrm{mg} / \mathrm{L}$ with a mean of $1.12 \mathrm{mg} / \mathrm{L}$. For all the major cations, only $\mathrm{Mg}^{2+}$ was found exceeding the desirable limit of $100 \mathrm{mg} / \mathrm{L}$ in three groundwater samples. It can be clearly seen from Figures 3(e)-3(h) that all these major cations of sampled groundwaters were concentrated in relatively low-value ranges, indicating desirable quality.

The major anions were dominated by $\mathrm{Cl}^{-}$, followed by $\mathrm{SO}_{4}{ }^{2-}$ and $\mathrm{HCO}_{3}{ }^{-}$(Figures 3(i)-3(k)). The concentration of these three anions was in the range of $108-1,353 \mathrm{mg} / \mathrm{L}$ for $\mathrm{Cl}^{-}, 109-659 \mathrm{mg} / \mathrm{L}$ for $\mathrm{SO}_{4}{ }^{2-}$, and $25-248 \mathrm{mg} / \mathrm{L}$ for $\mathrm{HCO}_{3}{ }^{-}$, with an average of $231 \mathrm{mg} / \mathrm{L}, 142 \mathrm{mg} / \mathrm{L}$, and $113 \mathrm{mg} / \mathrm{L}$, respectively. The portion of samples with $\mathrm{Cl}^{-}$exceeding the desirable limit of $250 \mathrm{mg} / \mathrm{L}$ was large, accounting for approximately $42.2 \%$ of the total sampled waters (Figure 3(i)). For $\mathrm{SO}_{4}{ }^{2-}$, majority $(88.9 \%)$ of the samples were observed within the desirable limit of $250 \mathrm{mg} / \mathrm{L}$ (Figure 3(j)). Thus, concerns on major anions should be focused on the relatively high content of $\mathrm{Cl}^{-}$. 
TABLE 1: The values of exposure parameters and RfD used in the HHAR model.

\begin{tabular}{|c|c|c|c|c|c|c|}
\hline \multirow{2}{*}{$\begin{array}{l}\text { Exposure } \\
\text { Parameter }\end{array}$} & \multicolumn{4}{|c|}{ Value } & \multirow{2}{*}{ Contaminant } & \multirow{2}{*}{$\begin{array}{c}\mathrm{RfD}_{\text {oral }} \\
(\mathrm{mg} /(\mathrm{kg} \times \text { day }))\end{array}$} \\
\hline & Infants & Children & Females & Males & & \\
\hline$\overline{\text { IR (L/day) }}$ & $0.65^{*}$ & $1.5^{*}$ & $2.66^{*}$ & $3.62^{*}$ & $\mathrm{~F}^{-}$ & $0.06^{* * *}$ \\
\hline EF (days/year) & $365^{* *}$ & $365^{* *}$ & $365^{*}$ & $365^{* *}$ & $\mathrm{Mn}$ & $0.14^{* *}$ \\
\hline ED (years) & $0.5^{*}$ & $6^{*}$ & $30^{*}$ & $30^{*}$ & $\mathrm{Fe}$ & $0.7^{* *}$ \\
\hline BW (kg) & $6.94^{*}$ & $25.9^{*}$ & $64.0^{*}$ & $73.0^{*}$ & & \\
\hline
\end{tabular}

*Zhai et al. [63]; ${ }^{* *}$ USEPA [60]; ${ }^{* * *}$ Zhang et al. [64].

Overall, groundwaters in the confined aquifers were predominantly of the Cl-Na type, with a few of the Mixed Cl$\mathrm{Mg}$.Ca type (2.2\%) and Cl-Ca type (2.2\%) (Figure 5). Generally, the relatively salty hydrochemical faces of groundwater like $\mathrm{Cl}-\mathrm{Na}$ type are potentially formed by the natural hydrochemical evolution, or external salinity contamination input like seawater intrusion and anthropogenic pollutants input $[9,23]$. Given the far away location from sea and poor water alternative ability in vertical, natural hydrochemical evolution was highly possible responsible for the salty $\mathrm{Cl}-\mathrm{Na}$ type of confined groundwater in the study area. Those relatively fresh hydrochemical facies, that is, Mixed $\mathrm{Cl}-\mathrm{Mg} \cdot \mathrm{Ca}$ type and $\mathrm{Cl}-\mathrm{Ca}$ type, were the results of groundwater chemical evolution at different stages.

Some minor elements like nitrogen, $\mathrm{F}^{-}, \mathrm{Zn}, \mathrm{Mn}$, and $\mathrm{Fe}$ were detected to get insight into their contents in the confined groundwater and potential effects on safe water utilization. Nitrogen including $\mathrm{NO}_{3}{ }^{-}, \mathrm{NO}_{2}{ }^{-}$, and $\mathrm{NH}_{4}{ }^{+}$was all below the desirable limits (Figures 3(l)-3(n)), suggesting safe contents. $\mathrm{Zn}$ in all sampled groundwaters was also observed within the desirable limit of $1 \mathrm{mg} / \mathrm{L}$. However, $\mathrm{F}^{-}$, $\mathrm{Mn}$, and Fe were found beyond the desirable limits in some samples. The content of $\mathrm{F}^{-}$varied from $0.40 \mathrm{mg} / \mathrm{L}$ to $1.97 \mathrm{mg} / \mathrm{L}$, with an average of $0.74 \mathrm{mg} / \mathrm{L}$. About $28.9 \%$ of samples were detected exceeding the desirable limit of $1 \mathrm{mg} / \mathrm{L}$. The concentrations of $\mathrm{Mn}$ and $\mathrm{Fe}$ in groundwater were in the range of $0.001-0.361 \mathrm{mg} / \mathrm{L}$ and $0.02-30.96 \mathrm{mg} / \mathrm{L}$, respectively, with an average of $0.014 \mathrm{mg} / \mathrm{L}$ and $1.09 \mathrm{mg} / \mathrm{L}$. It can be clearly seen that only a small portion $(15.6 \%)$ of samples had the Mn exceeding the desirable limit of $0.1 \mathrm{mg} / \mathrm{L}$ (Figure 3(q)), while high Fe groundwaters were widely distributed in the study area and $68.9 \%$ of the sampled groundwaters were observed beyond the desirable limit of $0.3 \mathrm{mg} / \mathrm{L}$ (Figure 3(r)). Thus, attention should be paid to the high $\mathrm{F}^{-}, \mathrm{Mn}$, and $\mathrm{Fe}$ in confined water as their negative health effects on human beings.

\subsection{Mechanisms Governing Groundwater Solute Chemistry.}

To reveal the mechanisms controlling groundwater solute chemistry in confined aquifers of the study area, hydrochemical diagrams, correlation matrix, and hydrogeochemical simulation were introduced in the present study. Generally, the hydrochemical compositions of natural water were dominantly governed by three mechanisms, namely, precipitation, rock, and evaporation dominance, which could be visibly revealed by the Gibbs diagrams. As shown in Figure 6, all sampled confined groundwaters were situated in the rock dominance of Gibbs diagrams, suggesting the solute chemistry of confined groundwater was naturally controlled by the rock-water interactions.

Besides the natural process, human activities are important external factors potentially regulating the hydrochemical composition of water. Nitrogen is an important indicator of pollution from the human community. As demonstrated in Figures 3(1)-3(n), all confined groundwaters in the study area had relatively low concentrations of nitrogen (including $\mathrm{NO}_{3}{ }^{-}, \mathrm{NO}_{2}{ }^{-}$, and $\mathrm{NH}_{4}{ }^{+}$). Generally, the $\mathrm{NO}_{3}{ }^{-}$concentration in natural conditions is below $10 \mathrm{mg} / \mathrm{L}$, and water with $\mathrm{NO}_{3}{ }^{-}$concentration below this natural limit is regarded as not influenced by human society. It can be clearly seen that almost all sampled groundwaters were dominantly with the $\mathrm{NO}_{3}{ }^{-}$concentration below $10 \mathrm{mg} / \mathrm{L}$ except for three samples slightly exceeding this natural limit, confirming nearly no anthropogenic pollutants inputted into the confined aquifers in the study area. Thus, the hydrochemistry of confined groundwater was only governed by the natural mechanism of rock-water interactions.

Various rocks can potentially be involved in the natural rock-water interactions during the groundwater circulation period. To constrain the potential contributed rocks, the end-member diagrams constructed by the ratio of $\mathrm{Ca}^{2+} / \mathrm{Na}^{+}$ versus $\mathrm{Mg}^{2+} / \mathrm{Na}^{+}$and $\mathrm{HCO}_{3}{ }^{-} / \mathrm{Na}^{+}$were performed in the present study. Rocks involved in natural rock-water interactions can be revealed from three end-members of rock types, that is, carbonates, silicates, and evaporites $[17,43,67]$. As demonstrated in Figure 7 , the sampled groundwaters were plotted in the dominance from the evaporites to the silicates, suggesting that the chemical solutes in the confined groundwater originated from the dissolution of evaporates and silicates. However, no sample was found located in the carbonates dominance, implying few contribution of carbonate minerals to groundwater chemistry.

The correlation matrix was introduced to further determine the contributions of evaporates and silicates to the hydrochemical components of confined aquifers. Significantly positive relations were observed between $\mathrm{Na}^{+}$and $\mathrm{Cl}^{-}$, with the correlation coefficient of 0.96 , implying the dissolution of halite (formula (1)) was one of the dominant processes controlling groundwater chemistry. This evidenced the aforementioned natural genesis of the salty hydrochemical face of $\mathrm{Cl}-\mathrm{Na}$ in confined aquifers. $\mathrm{Ca}^{2+}$ also showed a significant positive relation to $\mathrm{SO}_{4}{ }^{2-}$, suggesting the sulfate minerals dissolution (formulas (2) and (3)) dominantly contributed to the hydrochemical compositions in confined aquifers of the study area. These hydrochemical processes were evidenced by the saturation indexes (SI) 

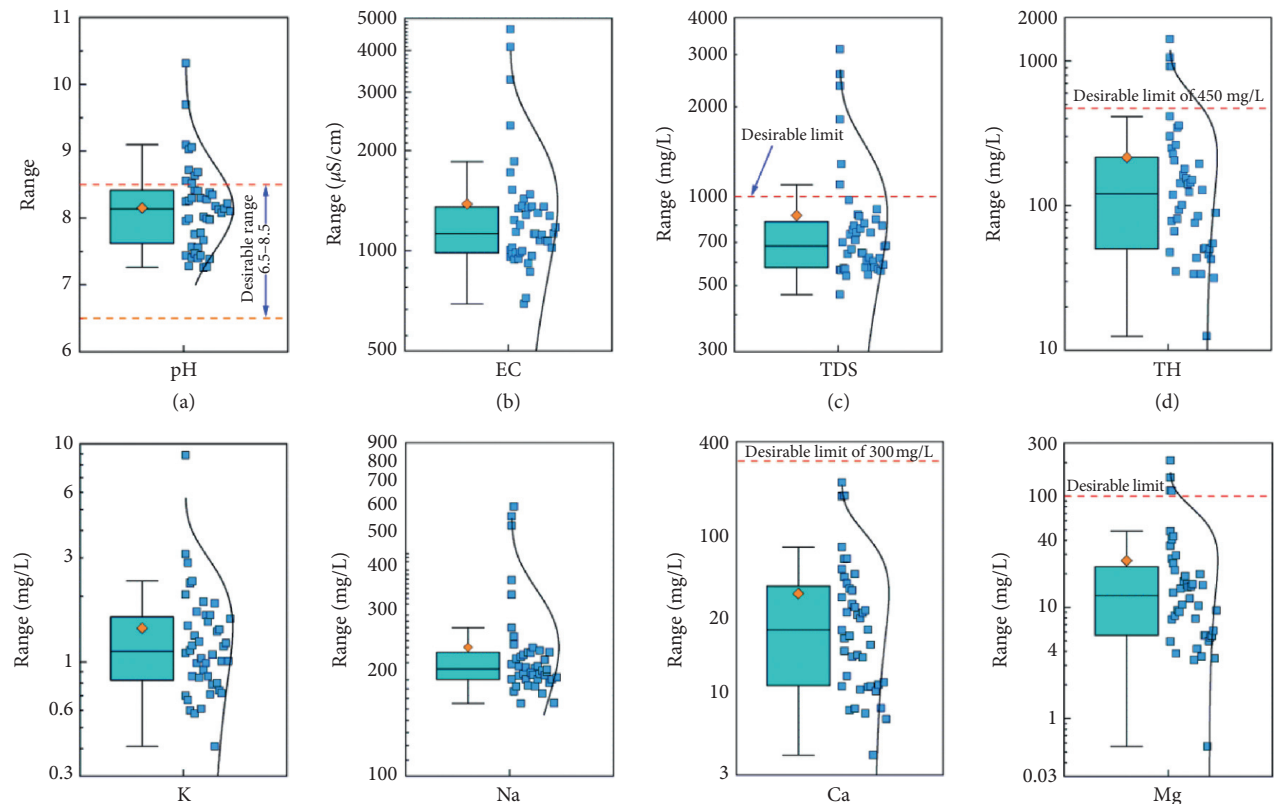

(e)
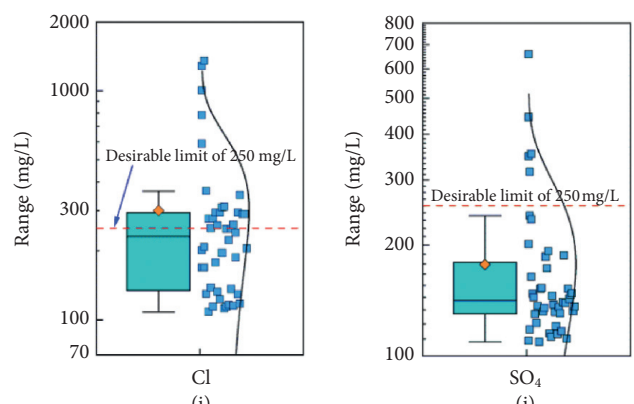

(g)
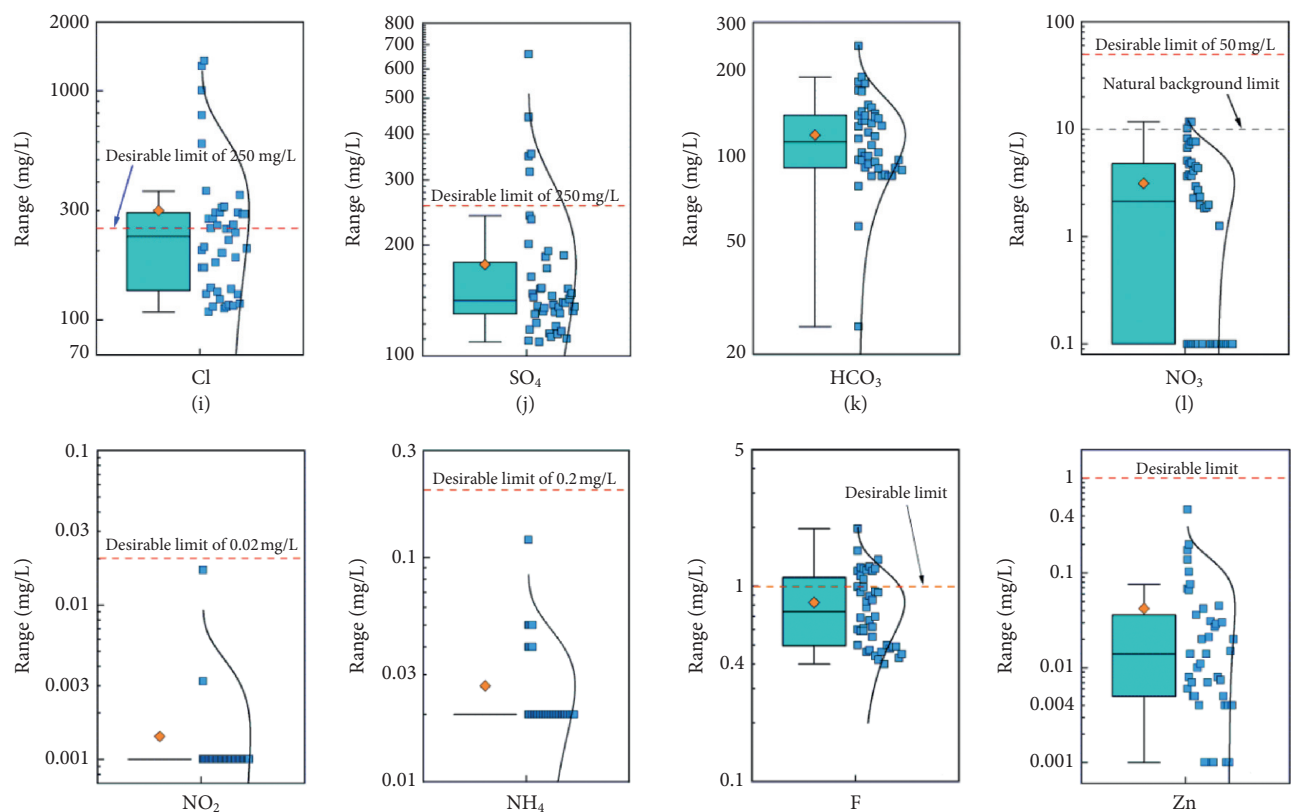

(k)
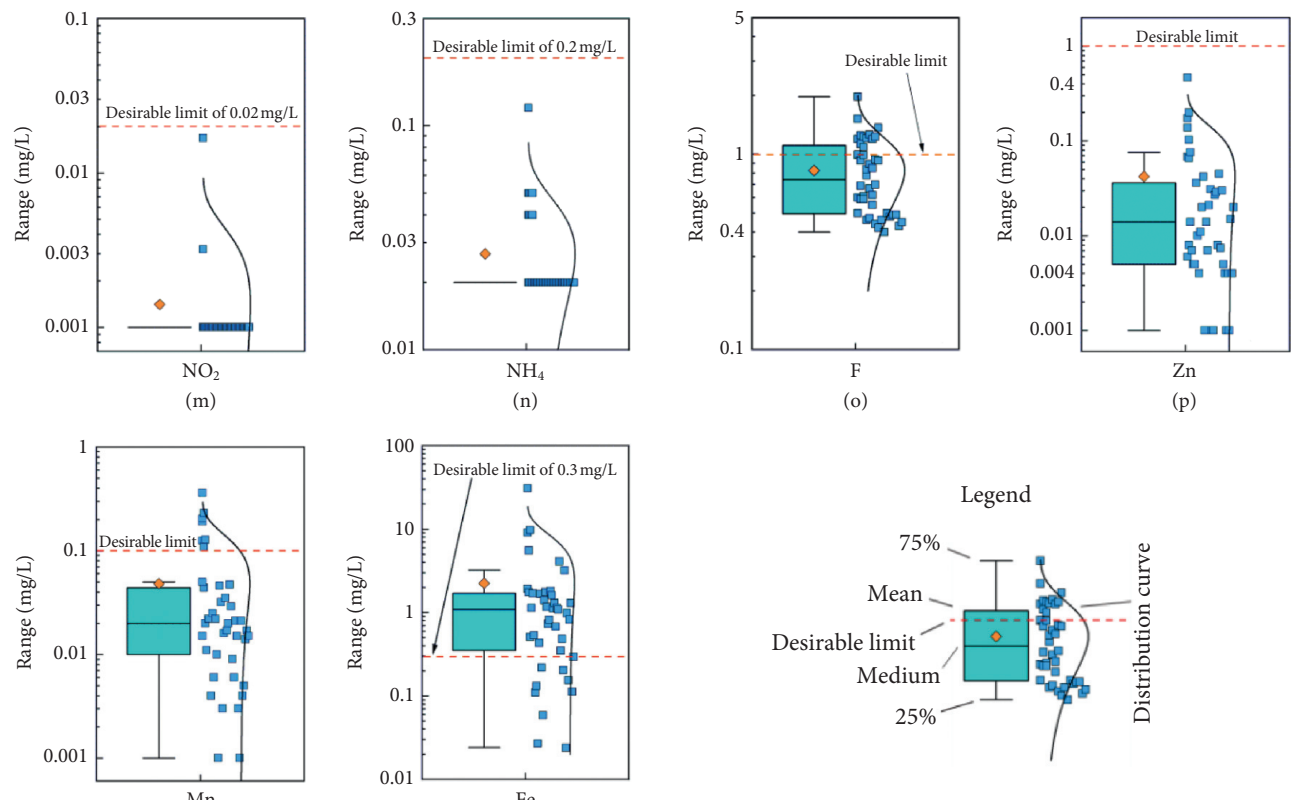

(n)

(o)

(p)
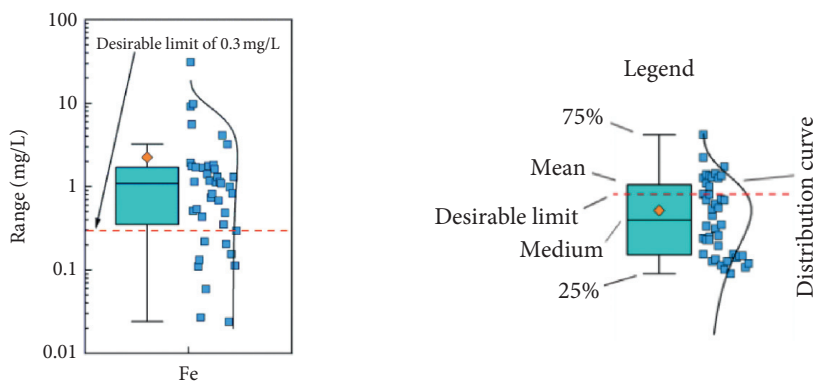

(q)

(r)

FIgURE 3: Box plots of physicochemical parameters of groundwater in the study area.

presented in Figure 8(a) that all sampled groundwaters were with unsaturated status $(\mathrm{SI}<0)$ of halite, anhydrite, and gypsum minerals. Additionally, the dissolution of silicates (formula (4)) was another dominant process contributing the major ions to groundwater, which was also demonstrated in Figure 7. The results of hydrochemical simulations 


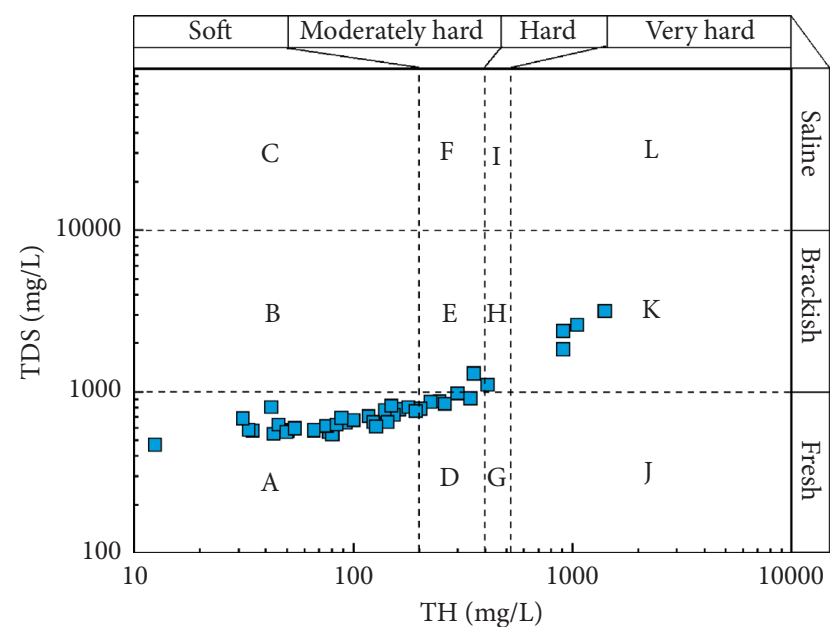

Figure 4: Scatter plots of total hardness (TH) versus total dissolved solids (TDS) showing the quality of groundwater.

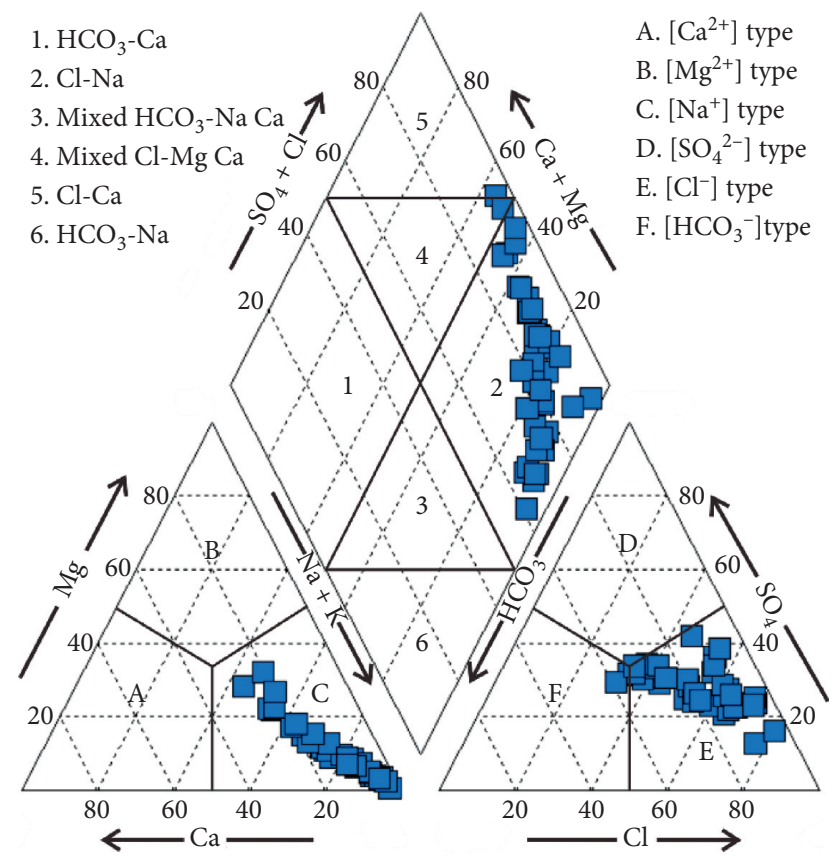

Figure 5: Piper diagrams demonstrating the hydrochemical compositions of groundwater in the study area.

also showed that all fluoride-bearing, Fe-bearing, and Mnbearing minerals were in the status of unsaturation (Figure 8(b)), suggesting the potential natural releasing of $\mathrm{F}^{-}, \mathrm{Mn}$, and $\mathrm{Fe}$ into groundwater from the aquifers' medium if these minerals exist. This was the reason for the relatively high contents of $\mathrm{F}^{-}, \mathrm{Mn}$, and $\mathrm{Fe}$ in some sampling groundwaters of the study area (Figures 3(o), 3(q), and 3(r)):

$$
\begin{aligned}
\mathrm{NaCl} & \longrightarrow \mathrm{Na}^{+}+\mathrm{Cl}^{-} \\
\mathrm{CaSO}_{4} \cdot 2 \mathrm{H}_{2} \mathrm{O} & \longrightarrow \mathrm{Ca}^{2+}+\mathrm{SO}_{4}{ }^{2-}+2 \mathrm{H}_{2} \mathrm{O} \\
\mathrm{CaSO}_{4} & \longrightarrow \mathrm{Ca}^{2+}+\mathrm{SO}_{4}{ }^{2-}
\end{aligned}
$$

$$
\begin{aligned}
& 2 \mathrm{NaAlSi}_{3} \mathrm{O}_{8}+2 \mathrm{CO}_{2}+11 \mathrm{H}_{2} \mathrm{O} \longrightarrow \mathrm{Al}_{2} \mathrm{Si}_{2} \mathrm{O}_{5}(\mathrm{OH})_{4} \\
& +4 \mathrm{H}_{4} \mathrm{SiO}_{4}+2 \mathrm{Na}^{+}+2 \mathrm{HCO}_{3}{ }^{-}
\end{aligned}
$$

Ions exchange is a common rock-water interaction occurring in aquifers, especially that with fine mediums. As demonstrated in Figure 2, there occurs many fine aquifers' mediums in the study area, which could potentially provide the sources of ions for the ions exchange processes. The chloro-alkaline indices, which could be expressed by CAI-1 (formula (5)) and CAI-2 (formula (6)), were introduced to determine whether the ions exchange processes occurred and contributed to the hydrochemical compositions of groundwater. Generally, if one water having all the two chloro-alkaline indices below 0 , indicating cation-exchange reaction (formula (7)) occurred; while, if reverse cation-exchange reaction (formula (8)) occurs, all chloro-alkaline indices would be positive. As shown in Figure 9(a), most (88.9\%) of sampled groundwaters were with negative chloro-alkaline indices, implying a cation-exchange reaction occurred there. The rest of the sampling groundwaters (G6, G29, G31, G39, G44) were found with positive negative chloro-alkaline indices, suggesting reverse cation-exchange reaction for these waters. These processes were examined using the relationship between $\mathrm{Na}^{+}+\mathrm{K}^{+}+\mathrm{Cl}^{-}$and $\mathrm{Ca}^{2+}+\mathrm{Mg}^{2+}-\mathrm{HCO}_{3}{ }^{-}-\mathrm{SO}_{4}{ }^{2-}$. Generally, if the cation-exchange reaction is the dominant process in the aquifers, groundwater should be plotted in the lower right dominance and along the $Y=-\mathrm{X}$ line. If the reverse cation-exchange reaction is the predominant hydrochemical mechanism in the aquifer, water should be situated in the upper left dominance of the diagram and along the $Y=-\mathrm{X}$ line. The bivariate diagram presented in Figure 9(b) evidenced the cation-exchange reaction for most groundwaters and reverse cation-exchange reaction for groundwaters of G6, G29, G31, G39, and G44:

$$
\begin{gathered}
\mathrm{CAI}-1=\frac{\mathrm{Cl}^{-}-\left(\mathrm{Na}^{+}+\mathrm{K}^{+}\right)}{\mathrm{Cl}^{-}} \\
\mathrm{CAI}-2=\frac{\mathrm{Cl}^{-}-\left(\mathrm{Na}^{+}+\mathrm{K}^{+}\right)}{\mathrm{HCO}_{3}^{-}+\mathrm{SO}_{4}{ }^{2-}+\mathrm{CO}_{3}^{-}+\mathrm{NO}_{3}^{-}} \\
\mathrm{Ca}^{2+}\left(\text { or } \mathrm{Mg}^{2+}\right)+2 \mathrm{NaX}(\text { solids }) \longrightarrow 2 \mathrm{Na}^{+} \\
+\mathrm{CaX}_{2}\left(\text { or } \mathrm{MgX}_{2}\right)(\text { solids }) \\
\left.2 \mathrm{Na}^{+}+\mathrm{CaX}_{2} \text { (or } \mathrm{MgX}_{2}\right)(\text { solids }) \longrightarrow \mathrm{Ca}^{2+}\left(\text { or } \mathrm{Mg}^{2+}\right) \\
+2 \mathrm{NaX} \text { (solids })
\end{gathered}
$$

The correlation matrix (Table 2) also demonstrated that the EC, TH, and TDS had a significant positive relation to the ions of $\mathrm{Na}^{+}, \mathrm{Ca}^{2+}, \mathrm{Mg}^{2+}$, and $\mathrm{Cl}^{-}$. Besides these four ions, the TH and TDS were also observed with significant positive relations to $\mathrm{SO}_{4}{ }^{2-}$. This evidenced that the hydrogeochemical processes discussed above predominantly contributed to the mineralization of confined groundwater in the study area. Overall, the solute chemistry of confined groundwater was dominantly controlled by the natural dissolution of evaporates (halite and sulfate) and silicates, cation-exchange 


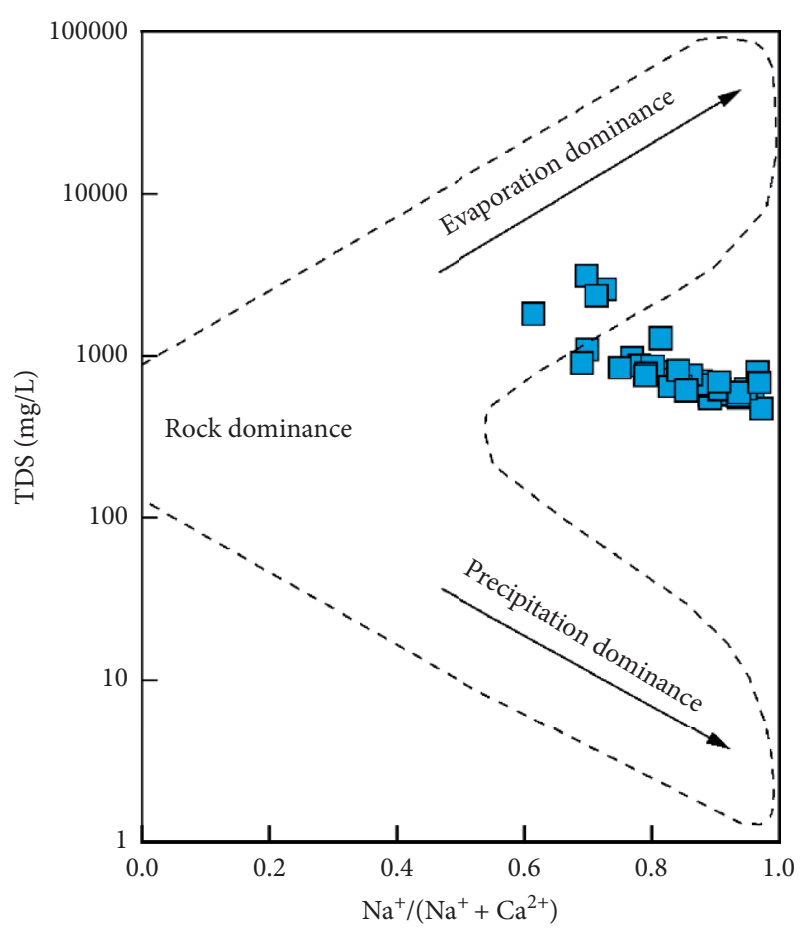

(a)

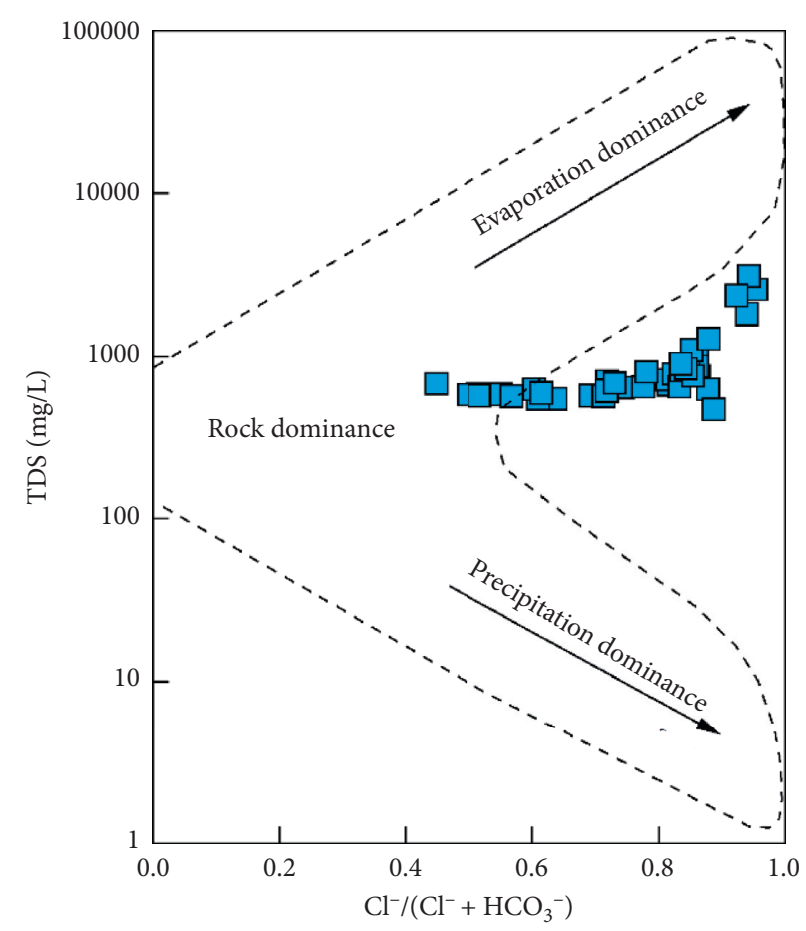

(b)

FIgURE 6: Gibbs diagrams demonstrating the natural mechanisms governing groundwater chemistry.

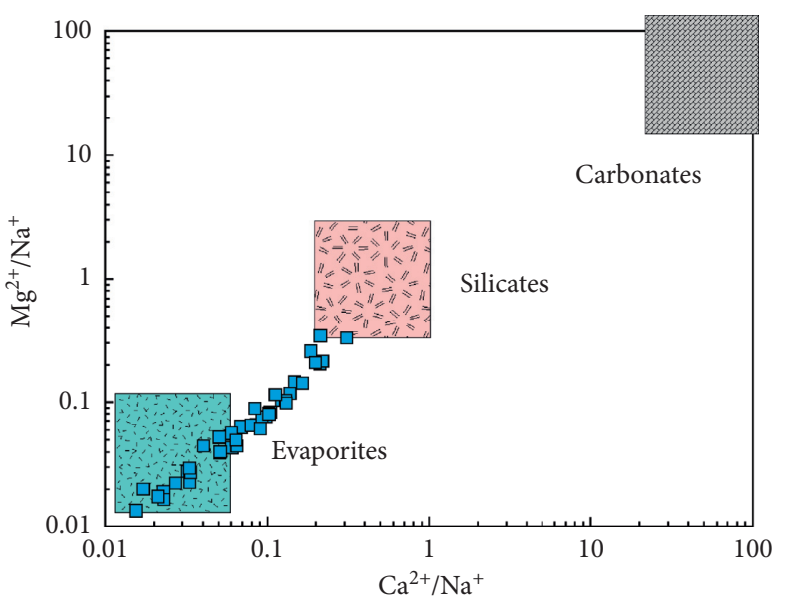

(a)

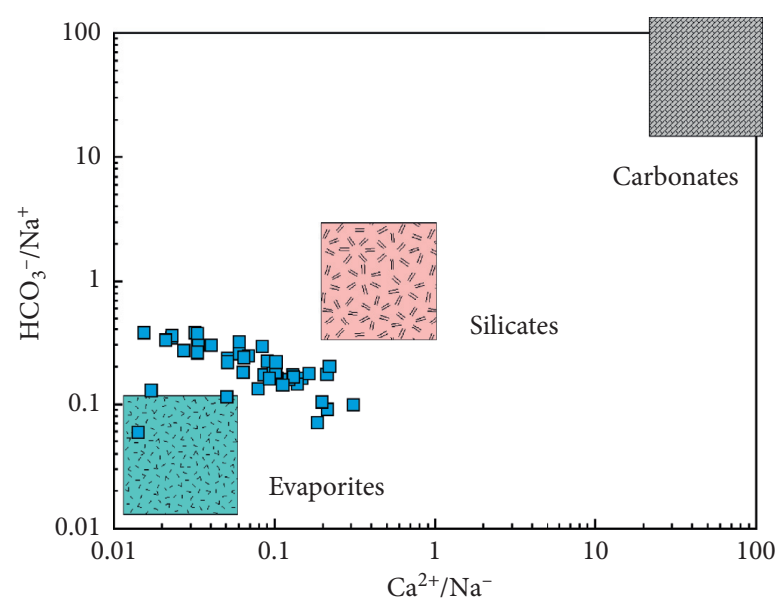

(b)

Figure 7: Scatter plots of (a) Na-normalized Ca versus Mg and (b) Na-normalized Ca versus $\mathrm{HCO}_{3}$.

reaction. The ions releasing from fluoride-bearing, Febearing, and Mn-bearing minerals contributed to the exceeding of $\mathrm{F}^{-}, \mathrm{Mn}$, and $\mathrm{Fe}$ in groundwater. Additionally, reverse cation-exchange reaction was also an important process influencing the hydrochemistry of confined groundwater at some sampling locations. However, the hydrogeochemical compositions of confined groundwater were nearly out of the influence of anthropogenic factors. 

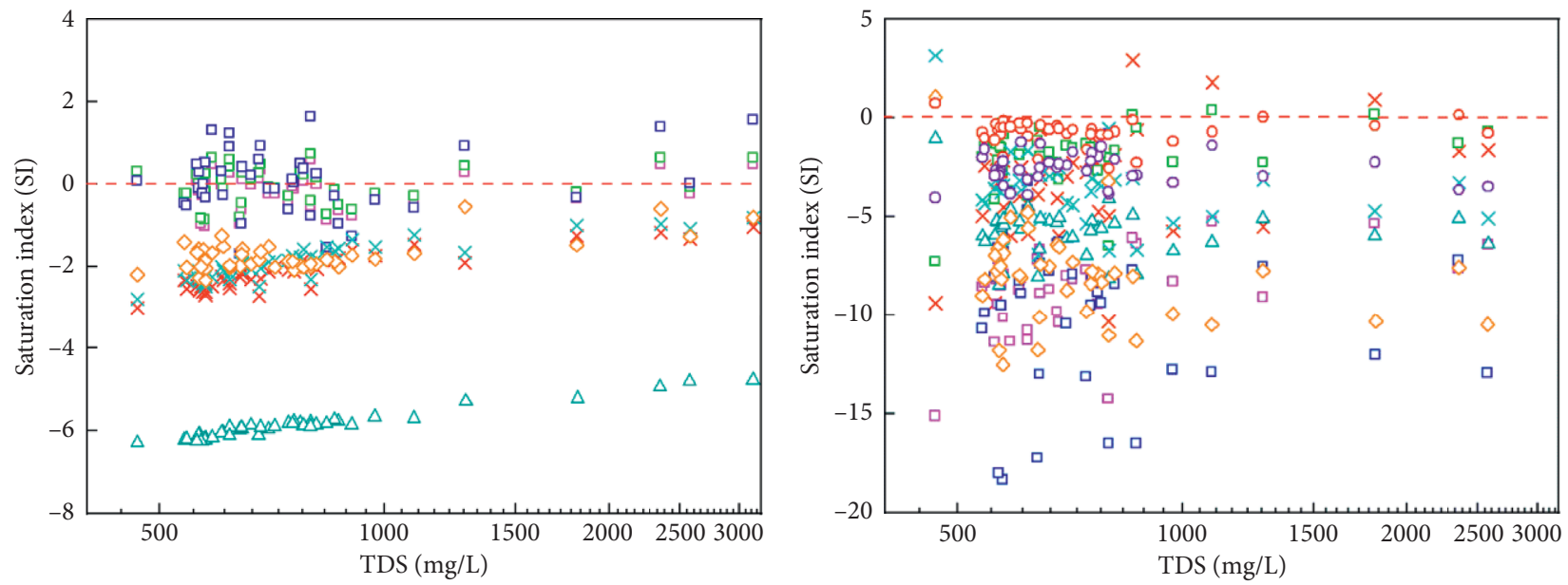

$\begin{array}{ll}\times \text { Anhydrite } & \times \text { Gypsum } \\ \square \text { Aragonite } & \triangle \text { Halite } \\ \square \text { Calcite } & \diamond \text { Fluoride } \\ \square \text { Dolomite } & \end{array}$

(a)
$\times$ Jarosite-K
口 Melanterite
$\checkmark$ Siderite
口 Hausm annite
$\times$ Manganite
$\triangle$ Pyrochroite
$\diamond$ Pyrolusite
- Rhodochrosite
- Smithsonite

(b)

FIGURE 8: Saturation index of selected minerals in groundwater of the study area.

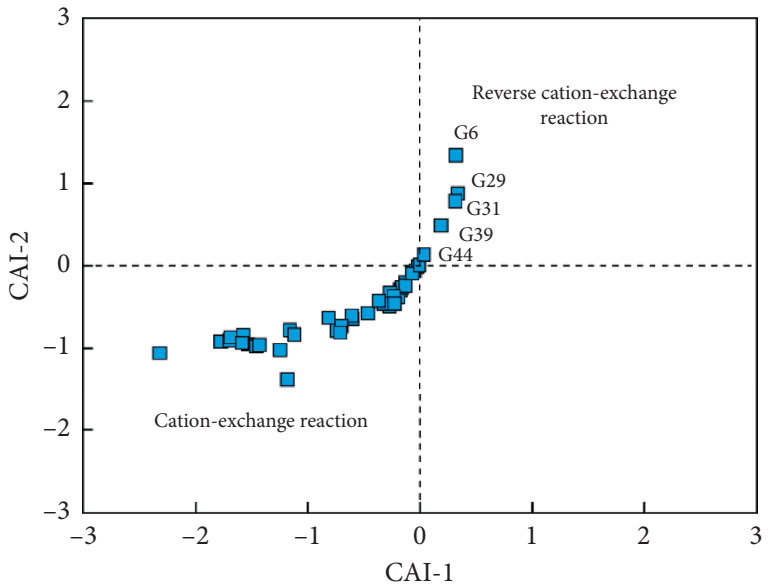

(a)

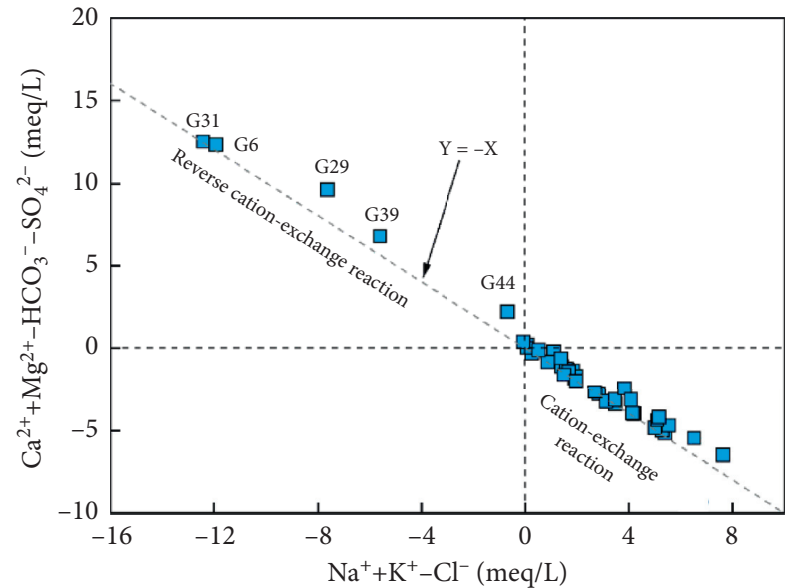

(b)

FIgUre 9: Scatter plots of (a) chloro-alkaline indices CAI-1 versus CAI-2 and (b) $\mathrm{Na}^{+}+\mathrm{K}^{+}-\mathrm{Cl}^{-}$versus $\mathrm{Ca}^{2+}+\mathrm{Mg}^{2+}-\mathrm{HCO}_{3}{ }^{-}-\mathrm{SO}_{4}{ }^{2-}$.

4.3. Potential Health Threats and Responsible Contaminants. As discussed above, the $\mathrm{F}^{-}$, $\mathrm{Mn}$, and Fe were detected with relatively high contents in groundwater and may pose negative effects on human health. The human health risk assessment model (HHRA model) was introduced to reveal the potential negative effects of these contaminants on human health.

According to the assessment results, the $\mathrm{HI}$ values were in the range of 0.67-4.99 for infants, $0.42-3.08$ for children, 0.30-2.21 for adult females and 0.36-2.64 for adult males, averaging at $1.60,0.99,0.71$, and 0.85 , respectively. It can be clearly seen that the overall health risks for various populations were in the order of infants $>$ children $>$ males $>$ females (Figure 10(a)). Similar results were also reported by many researchers [68-70]. The health risk can be classified into three categories, that is, low risk, medium risk, and high risk. Generally, an HI value less than 1 suggests the water with low and negligible health risk [71]. An HI value in the range of 1-4 is regarded as a medium health risk, and high health risk is implied if the $\mathrm{HI}$ value is beyond 4 $[55,72]$. Thus, all populations were at health risk to some degree. Specifically, the potential health risk for infants varied from low to high risk category (Figure 10(a)), with $24.4 \%$ in the low chronic risk category, $73.4 \%$ in the medium 
TABLE 2: Linear relationship (R2) between various chemical parameters of groundwater in the study area.

\begin{tabular}{|c|c|c|c|c|c|c|c|c|c|c|c|c|c|c|c|c|c|c|}
\hline Index & $p \mathrm{H}$ & EC & $\mathrm{TH}$ & TDS & $\mathrm{K}^{+}$ & $\mathrm{Na}^{+}$ & $\mathrm{Ca}^{2+}$ & $\mathrm{Mg}^{2+}$ & $\mathrm{Cl}^{-}$ & $\mathrm{SO}_{4}{ }^{2-}$ & $\mathrm{HCO}_{3}{ }^{-}$ & $\mathrm{NO}_{3}^{-}$ & $\mathrm{NO}_{2}^{-}$ & $\mathrm{NH}_{4}{ }^{+}$ & $\mathrm{F}^{-}$ & $\mathrm{Zn}$ & $\mathrm{Mn}$ & $\mathrm{Fe}$ \\
\hline $\mathrm{pH}$ & 1 & & & & & & & & & & & & & & & & & \\
\hline $\mathrm{EC}$ & -0.26 & 1 & & & & & & & & & & & & & & & & \\
\hline $\mathrm{TH}$ & -0.36 & $0.93^{*}$ & 1 & & & & & & & & & & & & & & & \\
\hline TDS & -0.28 & $0.97^{*}$ & $0.98^{*}$ & 1 & & & & & & & & & & & & & & \\
\hline $\mathrm{K}^{+}$ & 0.45 & -0.05 & -0.06 & -0.01 & 1 & & & & & & & & & & & & & \\
\hline $\mathrm{Na}^{+}$ & -0.17 & $0.95^{*}$ & $0.91^{*}$ & $0.97^{*}$ & 0.02 & 1 & & & & & & & & & & & & \\
\hline $\mathrm{Ca}^{2+}$ & -0.40 & $0.92^{*}$ & $0.99^{*}$ & $0.97^{*}$ & -0.07 & $0.89^{*}$ & 1 & & & & & & & & & & & \\
\hline $\mathrm{Mg}^{2+}$ & -0.33 & $0.94^{*}$ & $0.99^{*}$ & $0.99^{*}$ & -0.06 & $0.92^{*}$ & $0.97^{*}$ & 1 & & & & & & & & & & \\
\hline $\mathrm{Cl}^{-}$ & -0.30 & $0.97^{*}$ & $0.98^{*}$ & $0.99^{*}$ & -0.03 & $0.96^{*}$ & $0.96^{*}$ & $0.97^{*}$ & 1 & & & & & & & & & \\
\hline $\mathrm{SO}_{4}{ }^{2-}$ & -0.24 & 0.81 & $0.93^{*}$ & $0.93^{*}$ & 0.08 & $0.86^{*}$ & $0.90^{*}$ & $0.93^{*}$ & $0.87^{*}$ & 1 & & & & & & & & \\
\hline $\mathrm{HCO}_{3}^{-}$ & -0.10 & -0.12 & -0.12 & -0.05 & -0.41 & 0.06 & -0.16 & -0.08 & -0.14 & -0.01 & 1 & & & & & & & \\
\hline $\mathrm{NO}_{3}^{-}$ & -0.30 & -0.24 & -0.12 & -0.18 & 0.12 & -0.27 & -0.07 & -0.15 & -0.15 & -0.15 & -0.42 & 1 & & & & & & \\
\hline $\mathrm{NO}_{2}^{-}$ & 0.34 & -0.03 & -0.10 & -0.03 & $0.87^{*}$ & 0.04 & -0.12 & -0.09 & -0.08 & 0.08 & -0.08 & -0.14 & 1 & & & & & \\
\hline $\mathrm{NH}_{4}^{+}$ & -0.07 & -0.11 & -0.14 & -0.14 & -0.01 & -0.13 & -0.14 & -0.13 & -0.14 & -0.12 & 0.01 & 0.14 & 0.05 & 1 & & & & \\
\hline $\mathrm{F}^{-}$ & 0.36 & 0.09 & 0.04 & 0.13 & -0.06 & 0.27 & 0.01 & 0.07 & 0.09 & 0.10 & $0.50^{*}$ & $-0.62^{*}$ & 0.16 & -0.15 & 1 & & & \\
\hline $\mathrm{Zn}$ & -0.14 & 0.07 & 0.05 & -0.01 & -0.04 & -0.09 & 0.09 & 0.03 & -0.03 & 0.11 & -0.13 & 0.07 & -0.08 & -0.11 & -0.20 & 1 & & \\
\hline $\mathrm{Mn}$ & -0.01 & $0.67^{*}$ & 0.48 & 0.44 & -0.03 & 0.40 & $0.54^{*}$ & 0.43 & 0.45 & 0.36 & -0.23 & -0.25 & -0.10 & 0.01 & 0.10 & 0.18 & 1 & \\
\hline $\mathrm{Fe}$ & 0.11 & 0.01 & -0.03 & -0.05 & 0.02 & -0.06 & -0.01 & -0.04 & -0.05 & -0.02 & -0.14 & -0.01 & -0.07 & 0.20 & -0.15 & 0.06 & 0.46 & 1 \\
\hline
\end{tabular}

*significant relation (absolute value of correlation coefficient $>0.5$ ).

chronic risk category, and $2.2 \%$ in the high risk category. For children, adult females, and males, the potential overall health risks only fell in the low risk and medium risk category, and no high risk was observed (Figure 10(a)). Most of the sampled waters had the HI value below 1 for these three populations, accounting for $60.0 \%, 91.1 \%$, and $66.7 \%$ of the total sampled waters, respectively, suggesting negligible health risk in most of the area (Figure 11(b)-11(d)). Spatially, the potential health risk is distributed in the northern area surrounding the sampling site of G17 and the eastern area, as well as some sporadic areas adjacent to sampling sites like G22 and G4 (Figure 11).

For further illustrating the responsibility of each exceeding contaminant for the potential health risk, the HQ values of various contaminants for all populations are statistically presented in Figures 10(b)-10(d) with the aid of box plots. It can be seen that the HQ values of Mn for various populations were all below the permissible limit of 1 (Figure 10(c)), indicating negligible health threats from $\mathrm{Mn}$ in groundwater. For Fe in groundwater, the HQ values were dominantly (accounting for more than $90 \%$ of the sampled waters) below 1, and only very limited samples had the HQ value beyond the desirable limit of 1 (Figure 10(d)). For infants, one sample (2.2\%) and two samples (4.4\%) were found with high potential health risk and medium potential health risk from $\mathrm{Fe}$ in groundwater, respectively. Only one sample $(2.2 \%)$, that is, G17, was observed with potential health threats to children, adult females, and males, and all ranked in the medium risk category. However, the potential health hazards of $\mathrm{F}^{-}$were relatively higher than those of $\mathrm{Mn}$ and Fe in groundwater for all populations (Figures 10(b)$10(d))$. Out of the sampled groundwater, $57.8 \%, 26.7 \%$, $4.4 \%$, and $17.8 \%$ were under the category of medium potential health risks to infants, children, adult females, and males, respectively, in terms of $\mathrm{F}^{-}$in groundwater (Figure 10(b)). The statistic distribution of HQ posed by $\mathrm{F}^{-}$ was very similar to that of $\mathrm{HI}$ of multiple contaminants
(Figures 10(a) and 10(b)). All these indicated the exceeding $\mathrm{F}^{-}$in groundwater had higher responsibilities to the overall potential health risk than other contaminants in the study area.

4.4. Implication for Sustainable Water Management. As discussed above, groundwater is essential for the development of various aspects in the North China Plain. Confined groundwater is more precious for the middle and lower reaches of the North China Plain due to the widespread distribution of salty water in the shallow aquifers. Thus, it is significantly crucial to realize the sustainable management of groundwater resources in confined aquifers although existing some potentially toxic elements in the water.

Most of the confined groundwater is fresh and soft in the study area, suggesting desirable water quality for the utilization by the human community in terms of the major solute chemistry. Although the quality of confined groundwater was not affected by the anthropogenic factors, the natural toxic elements including $\mathrm{F}^{-}, \mathrm{Mn}$, and Fe exceeded the desirable limit for drinking purpose and would potentially pose threats to human society. Thus, these potential toxic elements should be paid attention to when the water is utilized as a domestic water resource. However, not all confined groundwater in the study area causes health threats to human beings, the attention should be concentratedly focused on the areas with potential threats by toxic elements. As aforementioned, the overall potential health threats mainly exist in the northern area surrounding the sampling site of G17 and the eastern area, as well as some sporadic areas adjacent to sampling sites like G22 and G4. Thus, other areas are safe for the utilization of confined groundwater resource.

For the potential risk areas mentioned above, the degree of health threats is different for various populations. Infants are more prone to the toxic elements in groundwater, and 


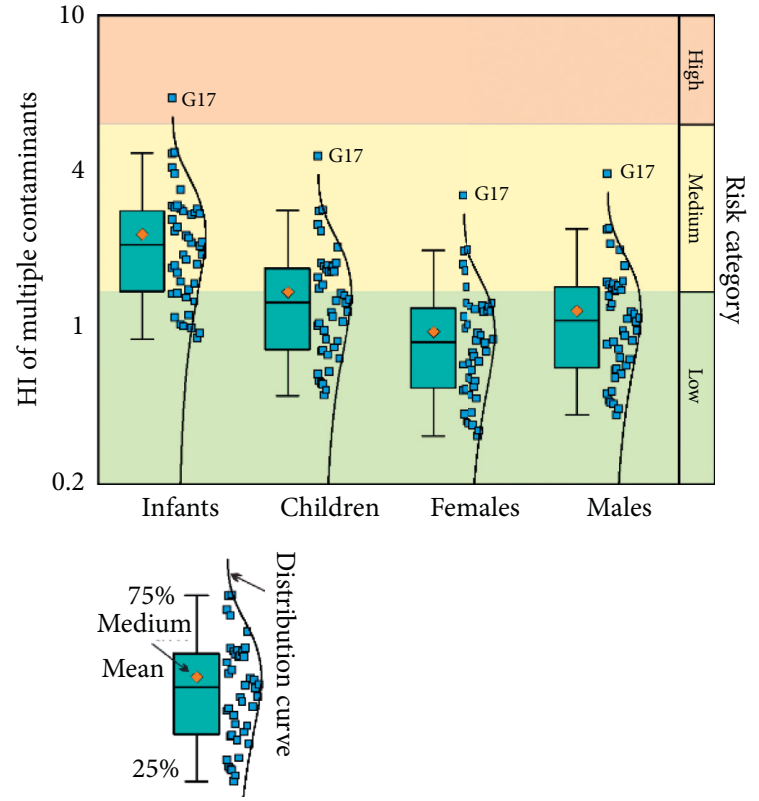

(a)
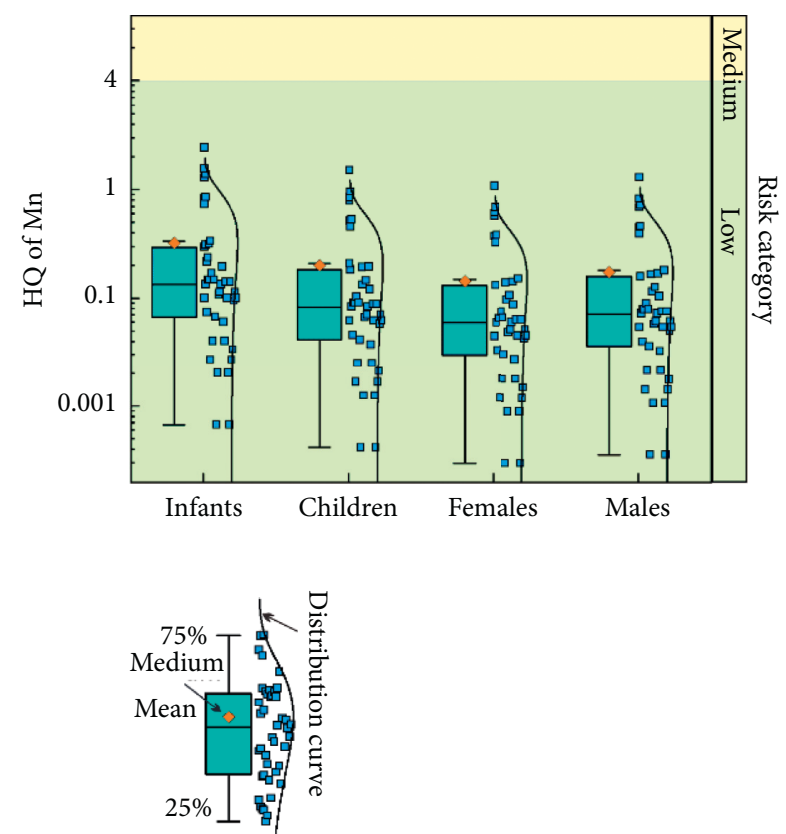

(c)

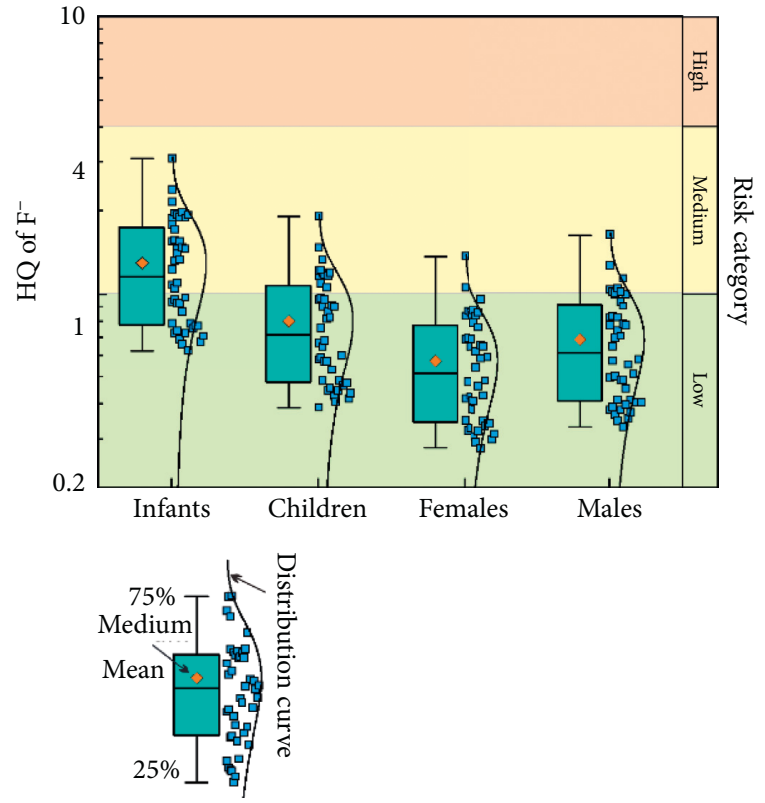

(b)
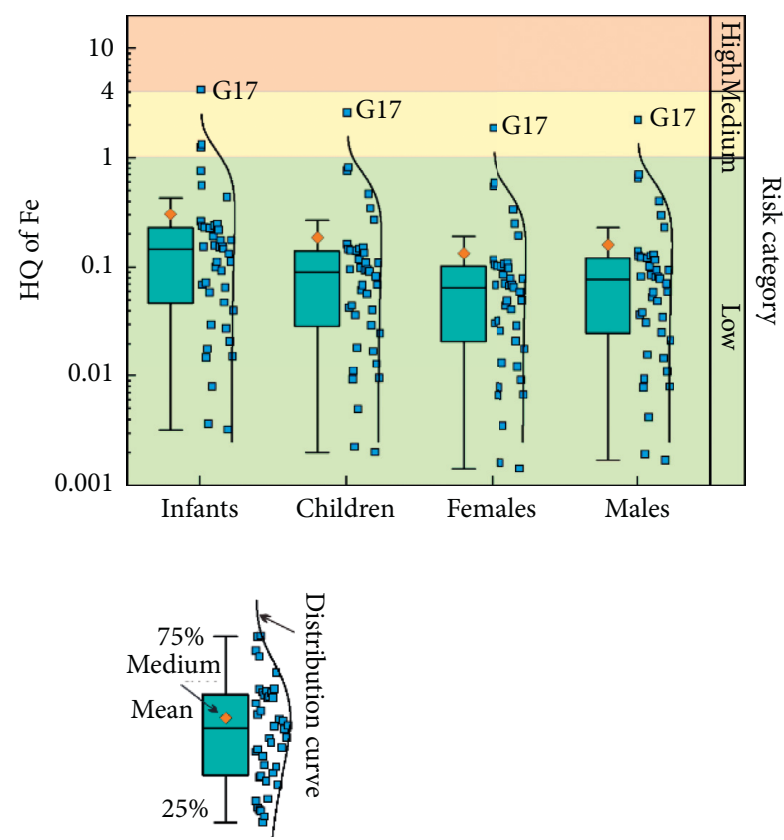

(d)

FIGURE 10: Box plots of (a) the overall noncarcinogenic health risk due to multiple contaminants and the hazard quotient of the noncarcinogenic health risk posed by a single contaminant of (b) $\mathrm{F}^{-}$, (c) $\mathrm{Mn}$, and (d) Fe.

the threats to children, adult females, and males are much less. Given the preciousness of confined groundwater resource, differential water supplies based on the potential health risk to various populations are recommended in the study area. Additionally, water quality improvement should be implemented in the potential risk area. Although $\mathrm{Mn}$ and
Fe are exceeding the desirable limit for water ingestion, their threats to human health are very limited and can be ignored. However, the health threat from the exceeding $\mathrm{F}^{-}$in groundwater is significant. Considering the economic feasibility, the water improvement measures should be carried out aiming at exceeding $\mathrm{F}^{-}$rather than other ions. 

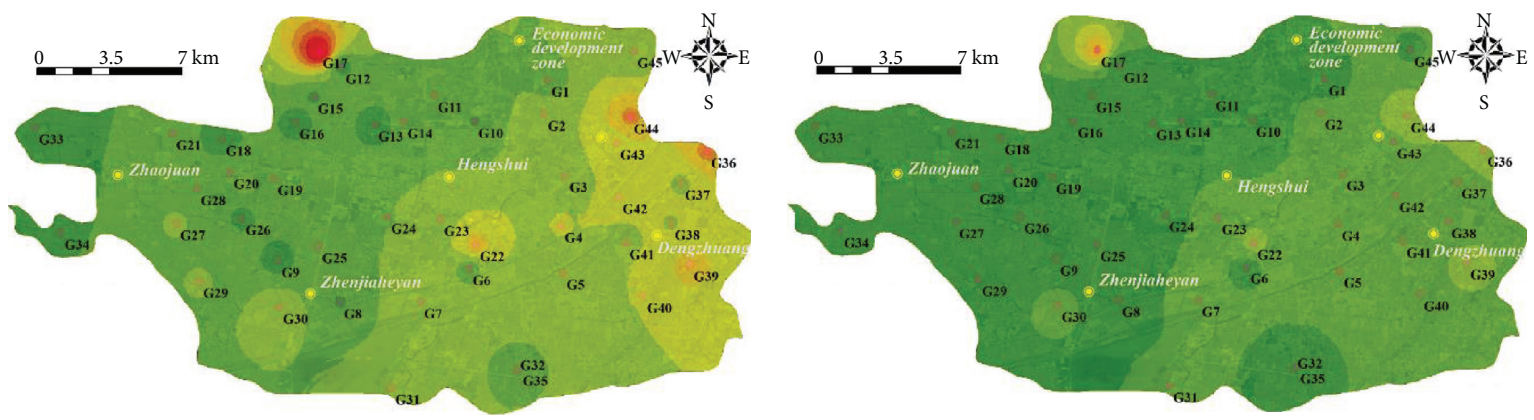

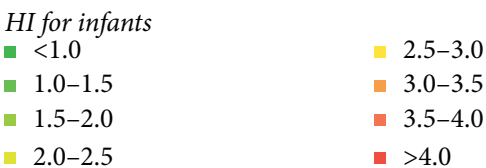

(a)

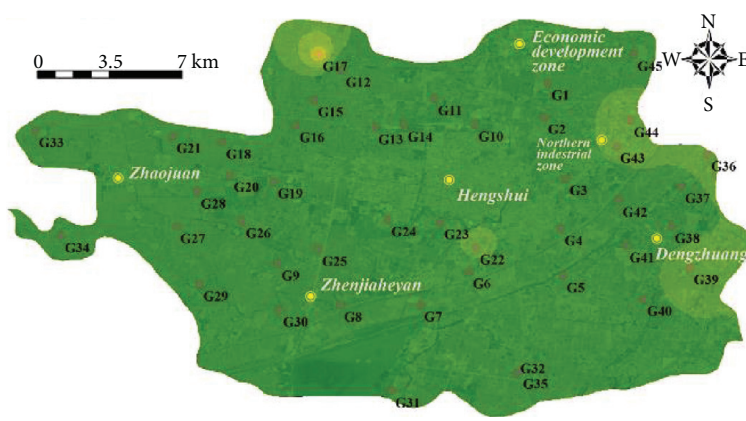

HI for infants

$\begin{array}{ll}-<1.0 & -1.5-2.0 \\ 1.0-1.5 & \end{array}$
HI for infants

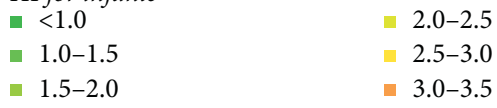

(b)

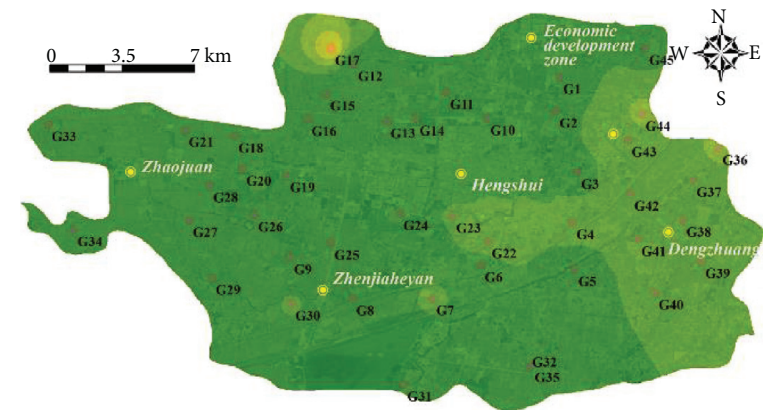

HI for infants

$\because<1.0$

- $2.0-2.5$

- $1.0-1.5$

- $1.5-2.0$

(d)

Figure 11: Distribution of the overall noncarcinogenic health risk to (a) infants, (b) children, (c) females, and (d) males.

\section{Conclusions}

Confined groundwater is the preferred water resource worldwide, especially in arid and semiarid regions with scarce surface water and poor quality of phreatic water. Hydrochemistry is the premise of available and sustainable confined groundwater and should be concerned preferentially. The urban area of Hengshui, North China Plain, was taken as the study area to get insight into the hydrochemistry and health perspective of confined groundwater in large sedimentary plains. The main findings are as follows:

(1) Confined groundwater was of nearly neutral to slightly alkaline nature in the study area. Groundwater was predominantly soft-fresh water with average TH and TDS of $121 \mathrm{mg} / \mathrm{L}$ and $681 \mathrm{mg} / \mathrm{L}$, respectively, and only a few samples in harder fresh or brackish categories. Hydrochemical facies were dominantly identified as $\mathrm{Cl}$-Na type, with a few of the Mixed Cl-Mg.Ca type (2.2\%) and Cl-Ca type (2.2\%). The majority of the groundwater samples had the major ions within the desirable limit of WHO, except for $6.7 \%, 11.1 \%$, and $42.2 \%$ of $\mathrm{Mg}^{2+}, \mathrm{SO}_{4}{ }^{2-}$, and $\mathrm{Cl}^{-}$, respectively. Nitrogen (including $\mathrm{NO}_{3}^{-}, \mathrm{NO}_{2}{ }^{-}$, and $\mathrm{NH}_{4}^{+}$) and $\mathrm{Zn}$ were in a low and safe content, while $\mathrm{F}^{-}, \mathrm{Mn}$, and $\mathrm{Fe}$ were found exceeding the recommended limit of WHO in $28.9 \%, 15.6 \%$, and $68.9 \%$ of the sampled groundwaters, respectively.

(2) The solute chemistry of confined groundwater was governed by the natural rock-water interactions and out of the effects of anthropogenic activities. The major hydrochemical composition and mineralization were dominantly contributed by the dissolution of evaporates (halite and sulfate) and silicates, cation-exchange reaction. Reverse cation-exchange reaction also controlled the major chemistry in sporadic samples. The exceeding content of toxic elements of $\mathrm{F}^{-}, \mathrm{Mn}$, and $\mathrm{Fe}$ was a result of ions releasing of fluoride-bearing, Fe-bearing, and $\mathrm{Mn}$ bearing minerals.

(3) The overall chronic health risk posed by multiple contaminants was in the order of infants $>$ children $>$ males $>$ females. The high health risk was only 
potentially existing for infants. Majority of groundwater samples had the potential health risk negligible to children (60.0\%), adult females (91.1\%), and males $(66.7 \%)$, but $73.4 \%$ of the sampled groundwater were with potential medium chronic health threats to infants. The exceeding $\mathrm{F}^{-}$was highly responsible for the potential health risk to residents. The exceeding $\mathrm{Fe}$ in a few water samples can also pose health threats to some degree, while the potential risk from $\mathrm{Mn}$ was very low and negligible.

(4) Most of the confined groundwaters had desirable hydrochemical quality for drinking purpose, but attention should also be paid to the exceeding geogenic toxic elements of $\mathrm{F}^{-}, \mathrm{Mn}$, and $\mathrm{Fe}$. The potential chronic health risk was dominantly posed by $\mathrm{F}^{-}$rather than $\mathrm{Mn}$ and $\mathrm{Fe}$ and at different levels. Differential water supplies based on the potential health risk to various populations are recommended. Water improvement measures should be conducted to eliminate the health threat from exceeding $\mathrm{F}^{-}$, especially to the infants.

\section{Data Availability}

The data used to support the findings of the present study will be provided upon request by the corresponding author.

\section{Conflicts of Interest}

The authors declare that they have no conflicts of interest.

\section{Acknowledgments}

This research was funded by the National Natural Science Foundation of China (42007183), the Fundamental Research Funds for the Central Universities (2682019CX14), the National Basic Resources Survey Program of China (2017FY100405), the China Geological Survey (DD20160238 and DD20190303), the Student Research Training Program of Southwest Jiaotong University (201015), and the Research Project on Teaching Reform of Southwest Jiaotong University (20201023-04).

\section{References}

[1] M. Ouarani, M. Bahir, D. J. Mulla et al., "Groundwater quality characterization in an overallocated semi-arid coastal area using an integrated approach: case of the essaouira basin, Morocco," Water, vol. 12, no. 11, 2020.

[2] T. Gleeson, K. Villholth, R. Taylor, D. Perrone, and D. Hyndman, "Groundwater: a call to action," Nature, vol. 576, no. 7786, p. 213, 2019.

[3] S. Jasechko, D. Perrone, K. M. Befus et al., "Global aquifers dominated by fossil groundwaters but wells vulnerable to modern contamination," Nature Geoscience, vol. 10, no. 6, pp. 425-429, 2017.

[4] B. Wang, Y. Teng, H. Wang et al., "Entropy weight method coupled with an improved DRASTIC model to evaluate the special vulnerability of groundwater in Songnen Plain, Northeastern China," Hydrology Research, vol. 51, no. 5, pp. 1184-1200, 2020.
[5] E. W. Banks, P. G. Cook, M. Owor et al., "Environmental tracers to evaluate groundwater residence times and water quality risk in shallow unconfined aquifers in sub Saharan Africa," Journal of Hydrology, 2020.

[6] M. Alqadi, A. Margane, M. Al Raggad et al., "Implementation of simple strategies to improve wellfield management in arid regions: the case study of wadi $\mathrm{Al}$ arab wellfield, Jordan," Sustainability, vol. 11, p. 21, 2019.

[7] S. Yin, Y. Xiao, X. Gu et al., "Geostatistical analysis of hydrochemical variations and nitrate pollution causes of groundwater in an alluvial fan plain," Acta Geophysica, vol. 67, no. 4, pp. 1191-1203, 2019.

[8] Y. Xiao, J. Shao, S. K. Frape et al., "Groundwater origin, flow regime and geochemical evolution in arid endorheic watersheds: a case study from the Qaidam Basin, northwestern China," Hydrology and Earth System Sciences, vol. 22, no. 8, pp. 4381-4400, 2018.

[9] P. Li, S. He, N. Yang, and G. Xiang, "Groundwater quality assessment for domestic and agricultural purposes in Yan'an City, northwest China: implications to sustainable groundwater quality management on the Loess Plateau," Environmental Earth Sciences, vol. 77, no. 23, 2018.

[10] W. Wang, Y. Chen, and W. Wang, "Groundwater recharge in the oasis-desert areas of northern Tarim Basin, Northwest China," Hydrology Research, vol. 51, no. 6, pp. 1506-1520, 2020.

[11] N. Subba Rao, B. Ravindra, and J. Wu, "Geochemical and health risk evaluation of fluoride rich groundwater in Sattenapalle Region, Guntur district, Andhra Pradesh, India," Human and Ecological Risk Assessment, vol. 26, no. 9, pp. 2316-2348, 2020.

[12] D. de Andrade Costa, J. P. Soares de Azevedo, M. A. dos Santos, and R. dos Santos Facchetti Vinhaes Assumpção, "Water quality assessment based on multivariate statistics and water quality index of a strategic river in the Brazilian Atlantic Forest," Scientific Reports, vol. 10, no. 1, 2020.

[13] F. Bouteldjaoui, M. Bessenasse, J.-D. Taupin, and A. Kettab, "Mineralization mechanisms of groundwater in a semi-arid area in Algeria: statistical and hydrogeochemical approaches," Journal of Water Supply: Research and Technology-Aqua, vol. 69, no. 2, pp. 173-183, 2019.

[14] K.-J. Lee, S.-T. Yun, S. Yu, K.-H. Kim, J.-H. Lee, and S.-H. Lee, "The combined use of self-organizing map technique and fuzzy c-means clustering to evaluate urban groundwater quality in Seoul metropolitan city, South Korea," Journal of Hydrology, vol. 569, pp. 685-697, 2019.

[15] S. Hajji, B. Ayed, I. Riahi, N. Allouche, E. Boughariou, and S. Bouri, "Assessment and mapping groundwater quality using hybrid PCA-WQI model: case of the Middle Miocene aquifer of Hajeb Layoun-Jelma basin (Central Tunisia)," Arabian Journal of Geosciences, vol. 11, no. 20, 2018.

[16] X. Gu, Y. Xiao, S. Yin et al., "Hydrogeochemical characterization and quality assessment of groundwater in a long-term reclaimed water irrigation area, north China plain," Water, vol. 10, no. 9, 2018.

[17] S. Venkatramanan, S. Y. Chung, S. Selvam, S. Y. Lee, and H. E. Elzain, "Factors controlling groundwater quality in the Yeonjegu District of Busan City, Korea, using the hydrogeochemical processes and fuzzy GIS," Environmental Science and Pollution Research, vol. 24, no. 30, pp. 23679-23693, 2017.

[18] X. Zhang, J. Miao, B. X. Hu, H. Liu, H. Zhang, and Z. Ma, "Hydrogeochemical characterization and groundwater quality assessment in intruded coastal brine aquifers (Laizhou Bay, 
China)," Environmental Science and Pollution Research, vol. 24, no. 26, pp. 21073-21090, 2017.

[19] P. J. S. Kumar and L. Kuriachan, "Chemometric appraisal of groundwater quality for domestic, irrigation and industrial purposes in Lower Bhavani River basin, Tamil Nadu, India," International Journal of Environmental Analytical Chemistry, 2020.

[20] Y. Li, J. Liu, Z. Gao, M. Wang, and L. Yu, "Major ion chemistry and water quality assessment of groundwater in the Shigaze urban area, Qinghai-Tibetan Plateau, China," Water Supply, vol. 20, no. 1, pp. 335-347, 2019.

[21] Y. Li, S. Hu, X. Cui et al., "The distribution and influencing factors of chromium in regional groundwater at Sanmenxia Basin north-central China," Desalination and Water Treatment, vol. 150, pp. 114-123, 2019.

[22] J. Li, Z. Shi, G. Wang, and F. Liu, "Evaluating spatiotemporal variations of groundwater quality in northeast beijing by selforganizing map," Water, vol. 12, no. 5, 2020.

[23] C. Li, X. Gao, S. Li, and J. Bundschuh, "A review of the distribution, sources, genesis, and environmental concerns of salinity in groundwater," Environmental Science and Pollution Research, vol. 27, no. 33, pp. 41157-41174, 2020.

[24] A. Shakoor, Z. Mahmood Khan, M. Arshad et al., "Regional groundwater quality management through hydrogeological modeling in LCC, west faisalabad, Pakistan," Journal of Chemistry, vol. 2017, Article ID 2041648, 16 pages, 2017.

[25] J. Pu, M. Cao, Y. Zhang, D. Yuan, and H. Zhao, "Hydrochemical indications of human impact on karst groundwater in a subtropical karst area, Chongqing, China," Environmental Earth Sciences, vol. 72, no. 5, pp. 1683-1695, 2014.

[26] X. Gao, X. Li, W. Wang, and C. Li, "Human activity and hydrogeochemical processes relating to groundwater quality degradation in the yuncheng basin, northern China," International Journal of Environmental Research and Public Health, vol. 17, no. 3, 2020.

[27] X. Gu, Y. Xiao, S. Yin et al., "Natural and anthropogenic factors affecting the shallow groundwater quality in a typical irrigation area with reclaimed water, North China Plain," Environmental Monitoring and Assessment, vol. 189, no. 10, 2017.

[28] C. P. S. Ahada and S. Suthar, "Groundwater nitrate contamination and associated human health risk assessment in southern districts of Punjab, India," Environmental Science and Pollution Research, vol. 25, no. 25, pp. 25336-25347, 2018.

[29] Y. Jia, B. Xi, Y. Jiang et al., "Distribution, formation and human-induced evolution of geogenic contaminated groundwater in China: a review," Science of The Total Environment, vol. 643, pp. 967-993, 2018.

[30] Y. Wang, X. Song, B. Li et al., "Temporal variation in groundwater hydrochemistry driven by natural and anthropogenic processes at a reclaimed water irrigation region," Hydrology Research, vol. 49, no. 5, pp. 1652-1668, 2018.

[31] P. Li, D. Karunanidhi, T. Subramani, and K. Srinivasamoorthy, "Sources and consequences of groundwater contamination," Archives of Environmental Contamination and Toxicology, vol. 80, no. 1, pp. 1-10, 2021.

[32] Y. Xiao, J. Shao, Y. Cui, G. Zhang, and Q. Zhang, "Groundwater circulation and hydrogeochemical evolution in Nomhon of Qaidam Basin, northwest China," Journal of Earth System Science, vol. 126, no. 2, 2017.

[33] S. Wang, X. Song, Q. Wang et al., "Shallow groundwater dynamics and origin of salinity at two sites in salinated and water-deficient region of North China Plain, China," Environmental Earth Sciences, vol. 66, no. 3, pp. 729-739, 2012.
[34] S. Tweed, M. Leblanc, I. Cartwright, G. Favreau, and C. Leduc, "Arid zone groundwater recharge and salinisation processes; an example from the Lake Eyre Basin, Australia," Journal of Hydrology, vol. 408, no. 3-4, pp. 257-275, 2011.

[35] S. Chen, Z. Tang, J. Wang et al., "Multivariate analysis and geochemical signatures of shallow groundwater in the main urban area of chongqing, southwestern China," Water, vol. 12, no. 10, 2020.

[36] S. Melki and M. Gueddari, "Impact assessment of phosphogypsum leachate on groundwater of sfax-agareb (southeast of Tunisia): using geochemical and isotopic investigation," Journal of Chemistry, vol. 2018, Article ID 2721752, 10 pages, 2018.

[37] K. K. Singh, G. Tewari, and S. Kumar, "Evaluation of groundwater quality for suitability of irrigation purposes: a case study in the udham singh nagar, uttarakhand," Journal of Chemistry, vol. 2020, Article ID 6924026, 15 pages, 2020.

[38] Y. Xiao, S. Yin, Q. Hao, X. Gu, Q. Pei, and Y. Zhang, "Hydrogeochemical appraisal of groundwater quality and health risk in a near-suburb area of North China," Journal of Water Supply: Research and Technology-Aqua, vol. 69, no. 1, pp. 55-69, 2020.

[39] S. Yin, Y. Xiao, P. Han et al., "Investigation of groundwater contamination and health implications in a typical semiarid basin of north China," Water, vol. 12, no. 4, 2020.

[40] J. Wu, P. Li, D. Wang, X. Ren, and M. Wei, "Statistical and multivariate statistical techniques to trace the sources and affecting factors of groundwater pollution in a rapidly growing city on the Chinese Loess Plateau," Human and Ecological Risk Assessment: An International Journal, vol. 26, no. 6, pp. 1603-1621, 2020.

[41] N. Subba Rao, B. Sunitha, N. Adimalla, and M. Chaudhary, "Quality criteria for groundwater use from a rural part of Wanaparthy District, Telangana State, India, through ionic spatial distribution (ISD), entropy water quality index (EWQI) and principal component analysis (PCA)," Environmental Geochemistry and Health, vol. 42, no. 2, pp. 579599, 2019.

[42] G. A. Stefania, M. Rotiroti, I. J. Buerge et al., "Identification of groundwater pollution sources in a landfill site using artificial sweeteners, multivariate analysis and transport modeling," Waste Management, vol. 95, pp. 116-128, 2019.

[43] O. A. Adeyeye, C. Xiao, Z. Zhang, A. S. Yawe, and X. Liang, "Groundwater fluoride chemistry and health risk assessment of multi-aquifers in Jilin Qianan, Northeastern China," Ecotoxicology and Environmental Safety, vol. 211, pp. 1-14, 2021.

[44] O. Rahmati, A. N. Samani, N. Mahmoodi, and M. Mahdavi, "Assessment of the contribution of $\mathrm{N}$-fertilizers to nitrate pollution of groundwater in western Iran (case study: ghorveh-dehgelan aquifer)," Water Quality, Exposure and Health, vol. 7, no. 2, pp. 143-151, 2015.

[45] S. Wang, S. Wei, H. Liang et al., "Nitrogen stock and leaching rates in a thick vadose zone below areas of long-term nitrogen fertilizer application in the North China Plain: a future groundwater quality threat," Journal of Hydrology, vol. 576, pp. 28-40, 2019.

[46] D. Marghade, D. B. Malpe, and N. Subba Rao, "Applications of geochemical and multivariate statistical approaches for the evaluation of groundwater quality and human health risks in a semi-arid region of eastern Maharashtra, India," Environmental Geochemistry and Health, vol. 43, no. 2, pp. 683-703, 2019. 
[47] M. Qasemi, M. Afsharnia, M. Farhang, A. Bakhshizadeh, M. Allahdadi, and A. Zarei, "Health risk assessment of nitrate exposure in groundwater of rural areas of Gonabad and Bajestan, Iran," Environmental Earth Sciences, vol. 77, no. 15, 2018.

[48] Y. Wang, J. Li, T. Ma, X. Xie, Y. Deng, and Y. Gan, "Genesis of geogenic contaminated groundwater: as, F and I," Critical Reviews in Environmental Science and Technology, pp. 1-39, 2020.

[49] J. Li, Y. Wang, C. Zhu et al., "Hydrogeochemical processes controlling the mobilization and enrichment of fluoride in groundwater of the North China Plain," Science of The Total Environment, vol. 730, 2020.

[50] H. Liu, H. Guo, L. Yang et al., "Occurrence and formation of high fluoride groundwater in the Hengshui area of the North China Plain," Environmental Earth Sciences, vol. 74, no. 3, pp. 2329-2340, 2015.

[51] C. Zhi, H. Chen, P. Li et al., "Spatial distribution of arsenic along groundwater flow path in Chaobai River alluvialproluvial fan, North China Plain," Environmental Earth Sciences, vol. 78, no. 8, 2019.

[52] M. Yousefi, V. Kazemi Moghaddam, S. Maghsoudi Nasab et al., "Northwest of Iran as an endemic area in terms of fluoride contamination: a case study on the correlation of fluoride concentration with physicochemical characteristics of groundwater sources in Showt," Desalination and Water Treatment, vol. 155, pp. 183-189, 2019.

[53] J. Podgorski and M. Berg, "Global threat of arsenic in groundwater," Science, vol. 368, p. 6493, 2020.

[54] X. He, P. Li, J. Wu, M. Wei, X. Ren, and D. Wang, "Poor groundwater quality and high potential health risks in the Datong Basin, northern China: research from published data," Environmental Geochemistry and Health, vol. 43, no. 2, pp. 791-812, 2021.

[55] Q. Hao, Y. Xiao, K. Chen, Y. Zhu, and J. Li, "Comprehensive understanding of groundwater geochemistry and suitability for sustainable drinking purposes in confined aquifers of the wuyi region, Central North China plain," Water, vol. 12, no. $11,2020$.

[56] P. Li and L. Ren, "Evaluating the effects of limited irrigation on crop water productivity and reducing deep groundwater exploitation in the North China Plain using an agro-hydrological model: II. Scenario simulation and analysis," Journal of Hydrology, vol. 574, pp. 715-732, 2019.

[57] L. Xing, H. Guo, and Y. Zhan, "Groundwater hydrochemical characteristics and processes along flow paths in the North China Plain," Journal of Asian Earth Sciences, vol. 71, pp. 250-264, 2013.

[58] X. Xue, J. Li, X. Xie, K. Qian, and Y. Wang, "Impacts of sediment compaction on iodine enrichment in deep aquifers of the North China Plain," Water Research, vol. 159, pp. $480-489,2019$.

[59] P. Li, "To make the water safer," Exposure and Health, vol. 12, no. 3, pp. 337-342, 2020.

[60] USEPA, Risk Assessment Guidance for Superfund, Volume I: Human Health Evaluation Manual (Part A), Interim Final, 1989.

[61] N. Adimalla and H. Qian, "Groundwater chemistry, distribution and potential health risk appraisal of nitrate enriched groundwater: a case study from the semi-urban region of South India," Ecotoxicology and Environmental Safety, vol. 207, pp. 1-10, 2021.

[62] M. Yousefi, M. Ghoochani, and A. Hossein Mahvi, "Health risk assessment to fluoride in drinking water of rural residents living in the Poldasht city, Northwest of Iran," Ecotoxicology and Environmental Safety, vol. 148, pp. 426-430, 2018.

[63] Y. Zhai, Y. Lei, J. Wu et al., "Does the groundwater nitrate pollution in China pose a risk to human health? A critical review of published data," Environmental Science and Pollution Research, vol. 24, no. 4, pp. 3640-3653, 2017.

[64] Y. Zhang, J. Wu, and B. Xu, "Human health risk assessment of groundwater nitrogen pollution in Jinghui canal irrigation area of the loess region, northwest China," Environmental Earth Sciences, vol. 77, no. 7, 2018.

[65] WHO, Guidelines for Drinking-Water Quality, World Health Organization, Geneva, Switzerland, 2011.

[66] GAQS, Standards for Groundwater Quality (GB/T 148482017), General Administration of Quality Supervision., Beijing, China, 2017.

[67] J. Siddique, J. Menggui, M. H. Shah, A. Shahab, F. Rehman, and U. Rasool, "Integrated approach to hydrogeochemical appraisal and quality assessment of groundwater from sargodha district, Pakistan," Geofluids, vol. 2020, Article ID 6621038, 15 pages, 2020.

[68] P. Li, X. He, and W. Guo, "Spatial groundwater quality and potential health risks due to nitrate ingestion through drinking water: a case study in Yan'an City on the Loess Plateau of northwest China," Human and Ecological Risk Assessment, vol. 25, no. 1-2, pp. 11-31, 2019.

[69] N. Adimalla and P. Li, "Occurrence, health risks, and geochemical mechanisms of fluoride and nitrate in groundwater of the rock-dominant semi-arid region, Telangana State, India," Human \& Ecological Risk Assessment, vol. 25, no. 1-2, pp. 81-103, 2018.

[70] Y. Zhou, P. Li, M. Chen, Z. Dong, and C. Lu, "Groundwater quality for potable and irrigation uses and associated health risk in southern part of Gu'an County, North China Plain," Environmental Geochemistry and Health, vol. 43, no. 2, pp. 813-835, 2020.

[71] P. Li, X. He, Y. Li, and G. Xiang, "Occurrence and health implication of fluoride in groundwater of loess aquifer in the Chinese loess plateau: a case study of tongchuan, northwest China," Exposure and Health, vol. 11, no. 2, pp. 95-107, 2018.

[72] B. U. Ukah, J. C. Egbueri, C. O. Unigwe, and O. E. Ubido, "Extent of heavy metals pollution and health risk assessment of groundwater in a densely populated industrial area, Lagos, Nigeria," International Journal of Energy and Water Resources, vol. 3, no. 4, pp. 291-303, 2019. 